\title{
Ionospheric scintillation monitoring and modelling
}

\author{
Yannick Béniguel ( $\left(^{1}\right)$, Vincenzo Romano ( $\left.{ }^{2}\right)$, Lucilla Alfonsi $\left({ }^{2}\right)$, Marcio Aquino $\left({ }^{3}\right)$, \\ Alain Bourdillon $\left({ }^{4}\right)$, Paul Cannon $\left({ }^{5}\right)$, Giorgiana De Franceschi $\left({ }^{2}\right)$, Smita Dubey $\left({ }^{6}\right)$, Biagio Forte $\left({ }^{7}\right)$, \\ Vadim Gherm $\left({ }^{8}\right)$, Norbert Jakowski $\left({ }^{6}\right)$, Massimo Materassi $\left({ }^{9}\right)$, Thoralf Noack $\left({ }^{6}\right)$, \\ Mariusz Pozoga $\left({ }^{10}\right)$, Niel Rogers $\left({ }^{5}\right)$, Paolo Spalla $\left({ }^{9}\right)$, Hal J. Strangeways $\left({ }^{11}\right)$, \\ E. Michael Warrington $\left({ }^{12}\right)$, Andrzej Wernik $\left({ }^{10}\right)$, Volker Wilken $\left({ }^{6}\right)$ and Nikolay Zernov $\left({ }^{8}\right)$ \\ ( $\left.{ }^{1}\right)$ IEEA, Paris, France \\ $\left(^{2}\right)$ Istituto Nazionale di Geofisica e Vulcanologia, Roma, Italy \\ $\left.{ }^{3}\right)$ Institute of Engineering Surveying and Space Geodesy, IESSG, Nottingham, UK \\ $\left({ }^{4}\right)$ IETR Université de Rennes 1, France \\ $\left(^{5}\right)$ Qinetiq, Malvern, $U K$ \\ $\left({ }^{6}\right)$ DLR, Neustrelitz, Germany \\ ${ }^{7}$ ) University of Nova Gorica, Slovenia \\ $\left(^{8}\right)$ University of St Petersburg, Russia \\ $\left.{ }^{9}\right)$ Institute for Complex Systems, National Council of Researches, Firenze, Italy \\ $\left({ }^{10}\right)$ Space Research Center, Warsaw, Poland \\ $\left.{ }^{11}\right)$ School of Electronic and Electrical Engineering, University of Leeds, UK \\ $\left.{ }^{12}\right)$ Department of Engineering, University of Leicester, UK
}

\begin{abstract}
This paper presents a review of the ionospheric scintillation monitoring and modelling by the European groups involved in COST 296. Several of these groups have organized scintillation measurement campaigns at low and high latitudes. Some characteristic results obtained from the measured data are presented. The paper also addresses the modeling activities: four models, based on phase screen techniques, with different options and application domains are detailed. Finally some new trends for research topics are given. This includes the wavelet analysis, the high latitudes analysis, the construction of scintillation maps and the mitigation techniques.
\end{abstract}

Key words scintillation - measurement campaigns - phase screen models - radar - wavelets - maps

\section{Introduction}

Transionospheric radio signals may experience amplitude and phase fluctuations due to the propagation through irregularities of the

Mailing address: Dr. Yannick Béniguel, IEEA 13, Promenade Paul Dumer, 92400 Courbevoie, France; e-mail: beniguel@ieea.fr electron density inside ionosphere. These irregularities develop after sunset under several deionization instability processes. They induce random fluctuations of the medium's refractive index. These signal fluctuations are referred as scintillation. The ionosphere scintillation is responsible for signal degradation from the VHF up to the $\mathrm{C}$ band. This can affect in particular, the performance of satellite based navigation systems.

The ionosphere drifts with respect to the earth at a velocity in the range of $100 \mathrm{~m} / \mathrm{s}$ at low latitudes. This drift velocity may reach values ten times higher at high latitudes. Due to 


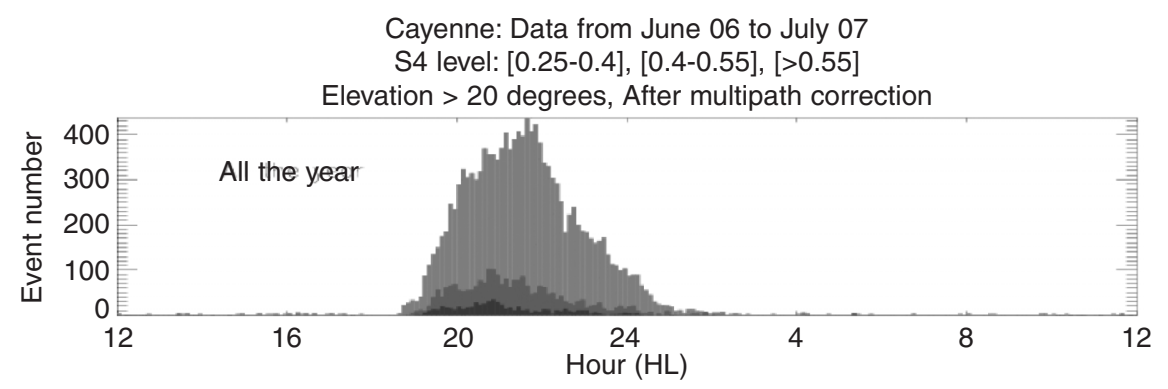

Fig. 1. $L$ band scintillation local time dependency measured in Cayenne $\left(4.82^{\circ} \mathrm{N} 52.36 \mathrm{~W}\right)$ during PRIS measurement campaign (courtesy CLS, Toulouse).
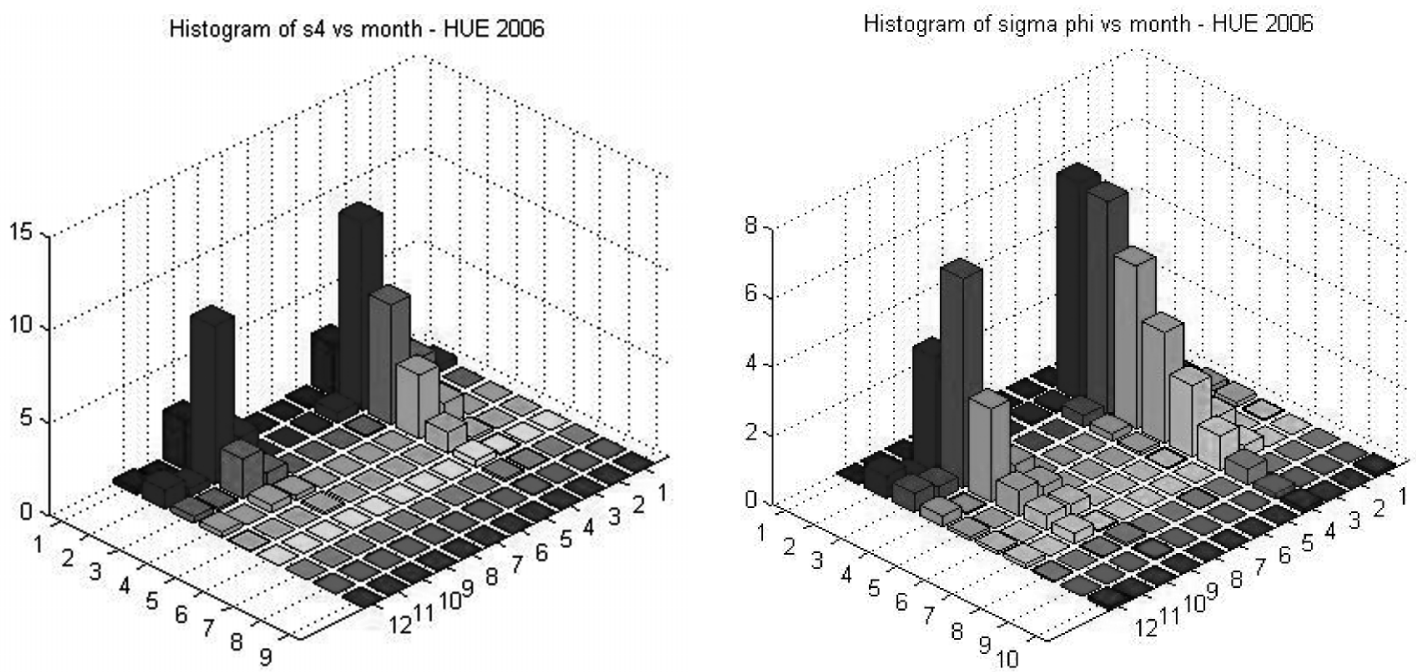

Fig. 2. Histogram of intensity and phase scintillations recorded in Vietnam (x axis $S_{4}$ to be multiplied by .1, $y$ axis the month number, $z$ axis the relative number of occurrences).

the respective motion of both the transmitter (satellite) and the medium with respect to the receiver, the signal received exhibits scintillations or deviations depending on the size of the irregularities and on the distance from the random medium to the receiver as compared to the Fresnel distance. The Multi-paths inside the medium cause phase fluctuation and concurrent intensity fluctuations. The normalised standard deviation of the received intensity $S_{4}$ (Briggs and Parkin, 1963) and the standard de- viation of the received phase $\sigma_{\phi}$ (Yeh and Liu, 1982) allow the scintillations to be classified into three categories: weak, medium or strong fluctuations. Observations show that the phase and intensity standard deviation (in radians for the phase and normalized for intensity) are correlated for low and medium fluctuations and uncorrelated for high fluctuations. In addition many characteristics can be studied such as the scattering function, the correlation properties, the probabilities, the fades statistics, the loss of 


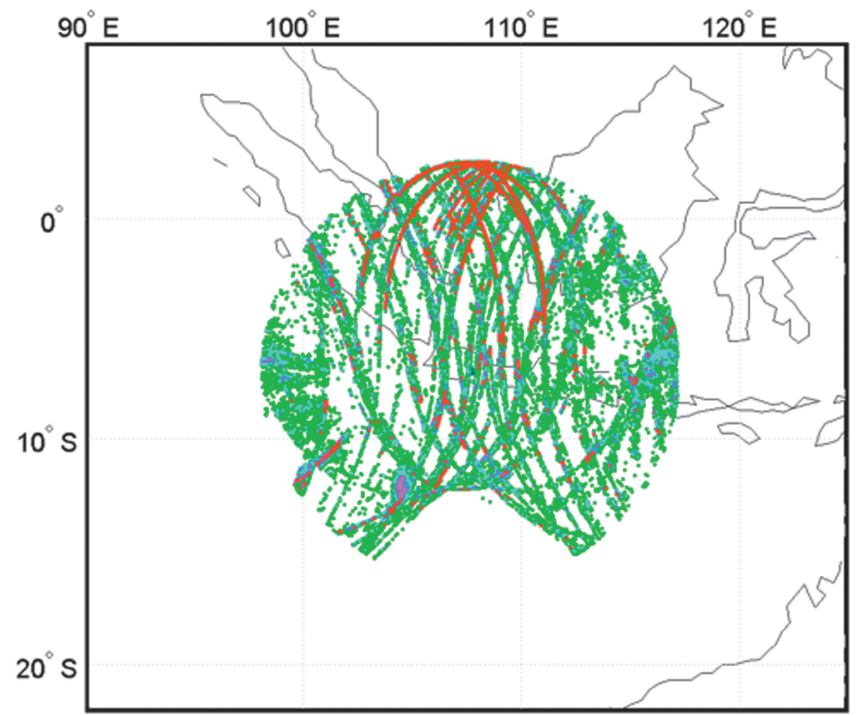

Fig. 3. Geographic distribution of $S_{4}$ at different levels measured at all satellites received in Bandung in 2006. All $S_{4}$ - indices measured with all GPS - satellites which are greater than 0.2 (green), greater than 0.3 (cyan), greater than 0.4 (magenta), greater than 0.5 (red) of the year 2006 are plotted at their corresponding sub-ionospheric locations.

lock, ... all these being of interest to develop mitigation techniques. Finally it should be mentioned that the scintillations occurrence and level are highly related to the solar and magnetic activity.

In the frame of the COST 296 action many institutions and companies have collaborated to study the scintillation phenomena. This was done by sharing the results of several measurement campaigns (as PRIS under ESA/ESTEC contract (Adam et al., 2008), coordinating the monitoring activity and collaborating for modeling development and data analysis. This paper reports on this collaborative activity and describes the main scientific results.

\section{Scintillation characteristics}

Scintillations are mainly observed over low latitudes at about $\pm 20^{\circ}$ around the magnetic equator and at auroral and polar zones. At high latitudes the scintillations are often caused by patches of enhanced ionization transported from the dayside subauroral latitudes across the polar cap into auroral oval. When these structures pass through the cusp they are fragmented into smaller-scale irregularities and form the polar cap patches.

At equatorial latitudes the ionospheric irregularities often form rod-like structures extending along the geomagnetic field lines to altitudes even higher than $1000 \mathrm{~km}$. Irregularities embedded inside these rods may cause intense scintillation effects on satellite radio links from the VHF up to the $\mathrm{C}$ band. Scintillations can exceptionally be observed at mid latitudes during intense ionospheric storms (see, e.g., De Franceschi et al., 2008).

The polar cap patches are predominantly a wintertime phenomenon: the polar cap has to be in darkness Hto observe ion patches. Nevertheless during summertime they are not absent. High plasma density exists in the dayside cusp and in the polar cap produced by direct photoionization. This latter condition minimizes 

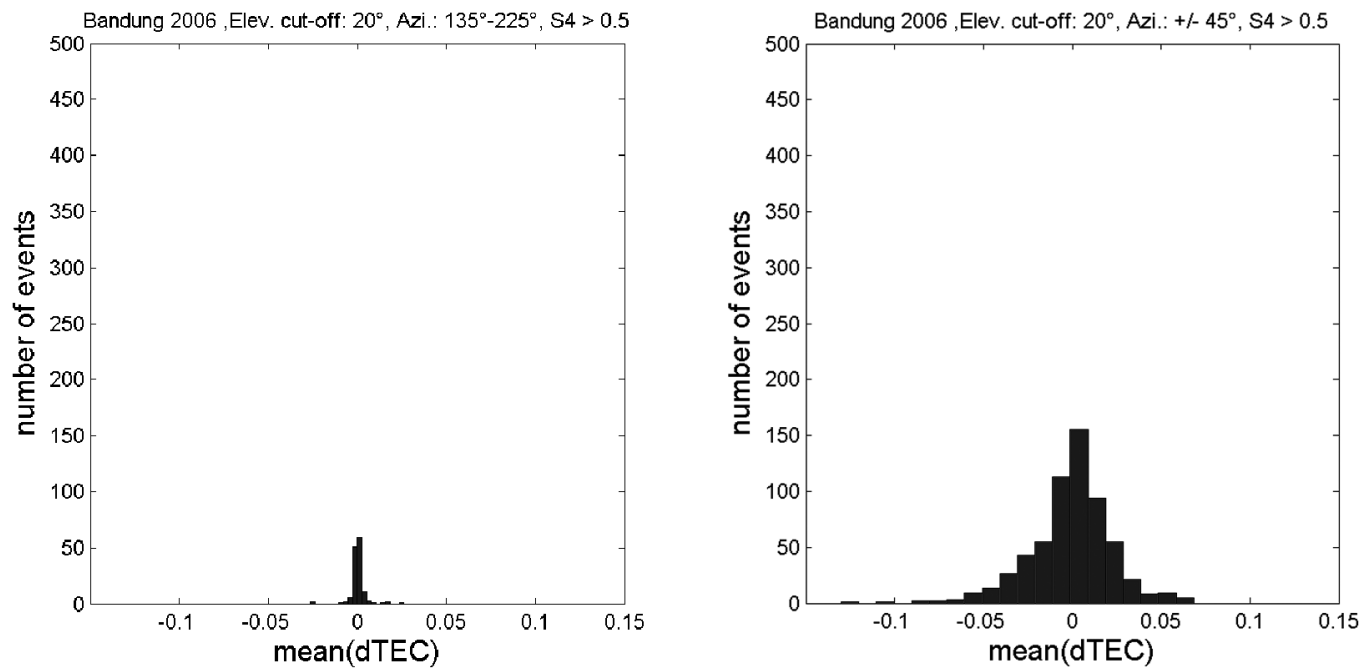

Fig. 4. Histogram of the mean TEC rate of change as a function of the direction: Southward (left panel) and Northward (right panel) of the Bandung station.
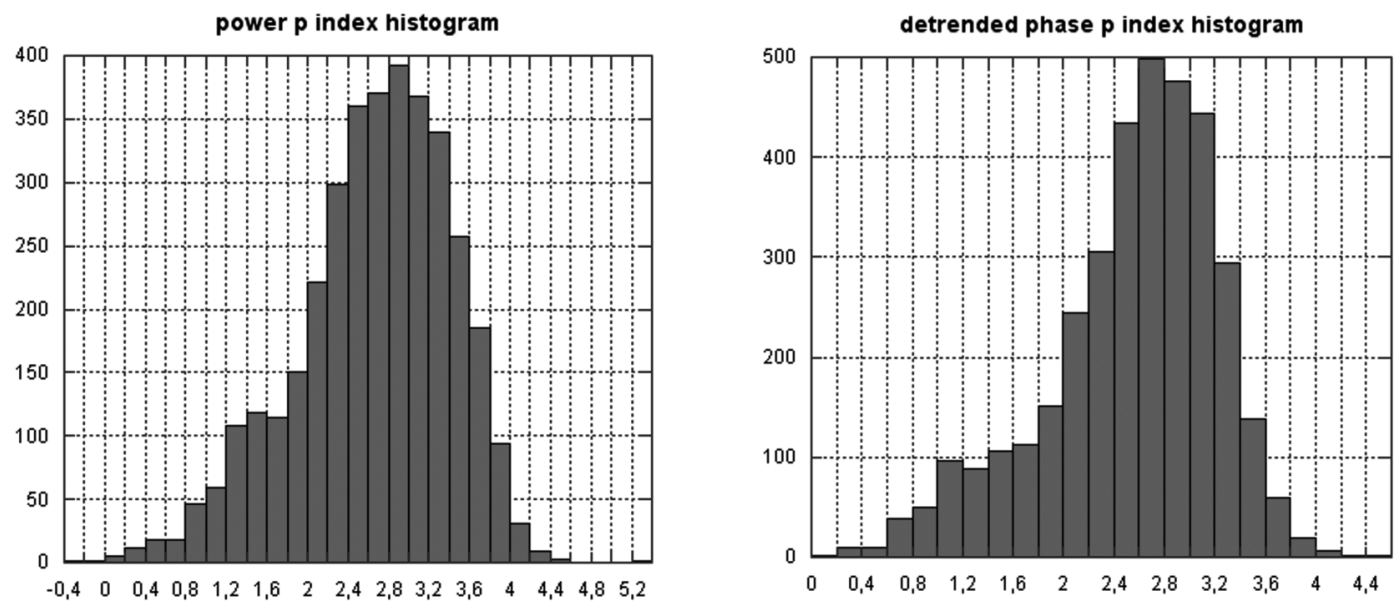

Fig. 5. Histograms of intensity and phase spectrum slope.

the formation of plasma density gradients.

The following plots show the local time, seasonal dependency, azimuth and elevation dependency and the spectrum.

Figure 2 below, corresponds to data recorded in Vietnam and presents the intensity $\left(S_{4}\right)$ and phase (sigma phi) standard deviations of scintillations depending on the month. It shows in that case, that the maximum of scintillation activity occurs during equinoxes.

To interpret the scintillation data correctly, their function of geometrical factors such as azimuth and elevation must be discussed. Taking into account the location of Bandung at about 
a
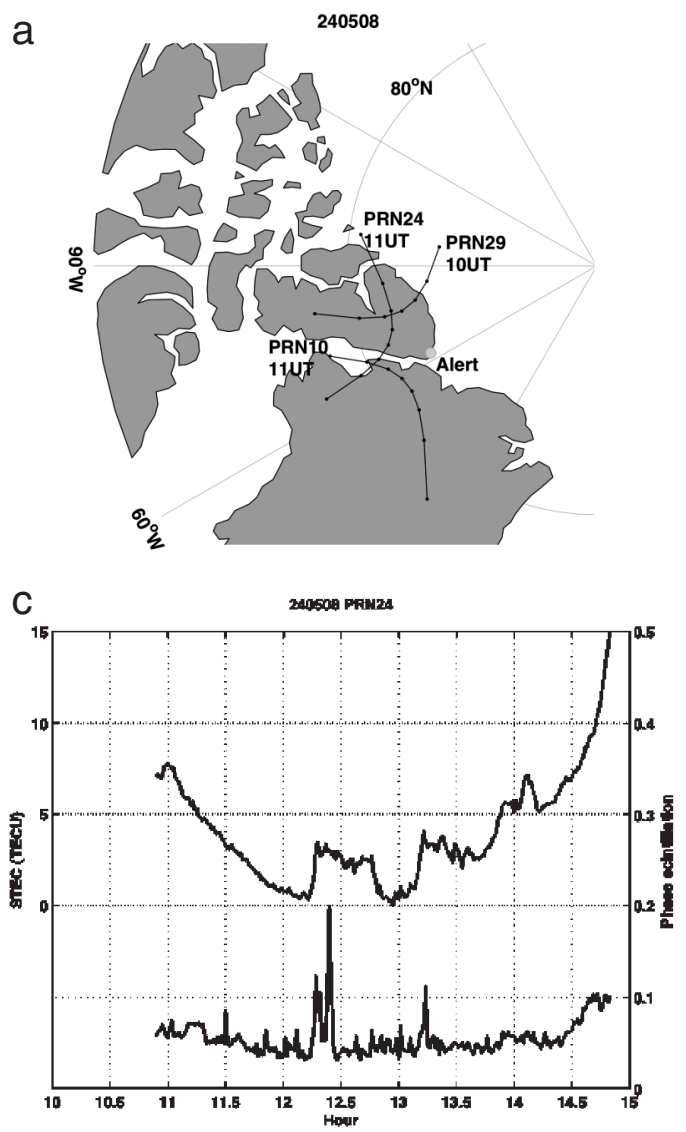

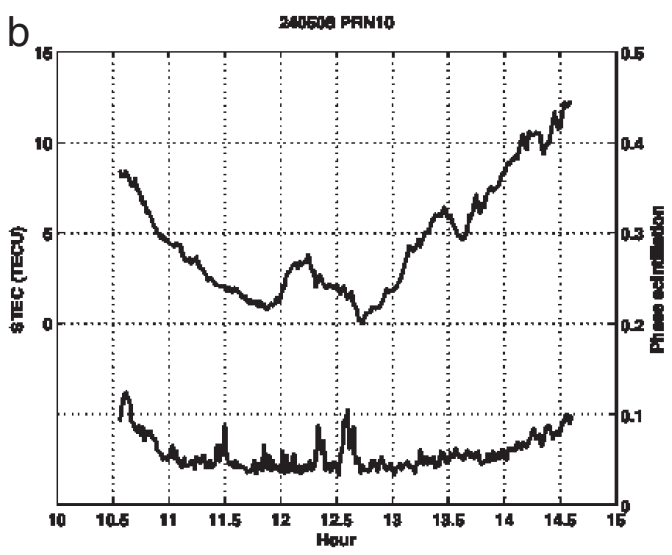

d

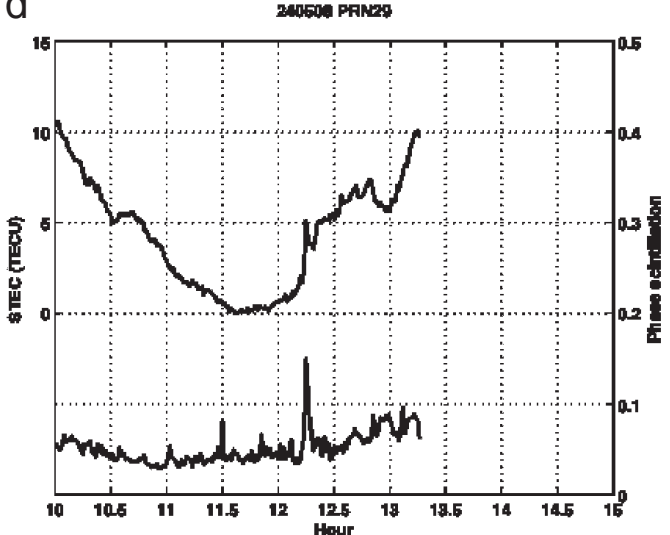

Fig. 6,a-b. Frame (a) indicates the tracks of the $250 \mathrm{~km}$ pierce points for satellites PRN10, PRN24 and PRN29 on 8 May 2008. The track starts at the labelled end of the trace at the time stated, and the dots indicate the movement of the pierce point at 30 minute intervals. Frames (b), (b) and (d) show the variation in slant TEC (offset such that the minimum observed value on that satellite pass is shown as zero) and phase scintillation $\left(\sigma_{\phi}\right)$ as a function of time for satellites PRN10, PRN24 and PRN29 respectively.

$7^{\circ} \mathrm{S}$ which is southward/below the southward equatorial anomaly crest region, ionospheric scintillations are expected mainly in northward direction at certain elevation angles related to ionospheric piercing points within the anomaly region.

As fig. 4 indicates, severe scintillations occur mostly northward of the Bandung station where the equatorial anomaly region is expected.

The strong North-South asymmetry is also well pronounced in the TEC rate. Considering the much higher electron density in the equatorial anomaly region, this result is expected.

The spectrum slope was calculated from the analysis of the raw data files recorded in Cayenne during the PRIS measurement campaign. Five days were used for this analysis. Only the samples exhibiting a $S_{4}$ value greater than 0.2 were considered. The results reported on fig. 5 , exhibit a peak value of 2.8 both for intensity and phase 
Figure 6 shows the Slant TEC and phase scintillation index $\left(\sigma_{\phi}\right)$ of the signals received from three satellites (PRN10, PRN24 and PRN29) observed at Alert on 24 May 2008. A very clear example of the presence of a series of polar patches is shown in frame (c) of this figure in which marked increases in STEC on the path from satellite PRN24 associated with the steep electron density gradients corresponding to 3 polar patches are evident.

Peaks in phase scintillation corresponding to either the beginning or end of the time history of the STEC increase are often evident. One patch is observed in the signal received from satellite PRN29 (frame (d)) that has a large peak in phase scintilation associated with the leading edge (in time) of the patch. For the three patches evident in the measurements from satellite PRN24 (frame (c)), the first two have peaks in phase scintillation corresponding to the leading edge (in time) of the patches. In contrast, the signal received from the third satellite (PRN10) exhibits a different behavior (see frame (b)). In this case, the increase in phase scintillation is observed on the trailing (in time) edge of the patch. It is important to note, that at the current stage of investigation, it is not clear which physical edge of the patches correspond to the edges observed in the time history (note that the speed of motion of the pierce point of the path from satellite to receiver and the speed of the patches have the same order of magnitude, and it is therefore possible to observe the physically trailing edge of a patch before the leading edge). Nevertheless, the general behaviour of the signals received from all three satellites indicates that the border of the $F$-layer patches is occupied by smaller scale electron density irregularities that cause increases in phase scintillation.

\section{Measurements}

The COST 296 action has contributed to support and coordinate the ionospheric scintillation monitoring activity using high sampling rate GPS amplitude and phase measurements. Several European institutions have installed and managed scintillation receivers both at high and low latitudes. A description of the monitoring activities follows.

The INGV contributed by the project «Ionospheric Scintillations Arctic Campaign Coordinated Observation (ISACCO)». ISAC$\mathrm{CO}$ was born at the beginning of 2003 as a proposal submitted to the call for opportunity 2003-2004 for access to the CNR (Italian National Research Council) Arctic Italian station «Dirigibile Italia» (79.9N, 11.9E, Ny Alesund, Svalbard, Norway). After a positive outcome of the application, in September 2003 the first GISTM (GPS Ionospheric and TEC Monitor, (Van Dierendonck et al., 1993) receiver was installed at Ny Alesund by INGV, Roma. In 2004, a second receiver was located about $1 \mathrm{~km}$ away from the first one and a third receiver was set up in Longyearbyen, $125 \mathrm{~km}$ from the other two. In January 2006, another GISTM was installed at the «Mario Zucchelli» Italian Antarctic station, Terra Nova Bay (74.7S, 164.1E) and in January 2008 another receiver was deployed at the Italian-French Antarctic station of Concordia at Dome C (75.0S, 123.0E), on the Antarctic plateau.

In the frame of the PRIS measurement campaign, IEEA installed a GSV 4004 receiver in N'Djamena, Chad, in 2006, still in operation. The location was chosen to obtain data from Africa, in the same region as those collected by the ESA/ESTEC receiver installed in Douala, Cameroon. The data collected from these two receivers have been stored into the PRIS data base together with those collected by receivers operated by University of Rennes in Vietnam, CLS company (Toulouse) in Cayenne, GMV company (Madrid) in the Canary Islands and DLR (see table I).

The three DLR receivers are installed at high (Kiruna, Sweden) and low latitudes (Puerto de la Cruz, Tenerife, Canary Islands and Bandung, Indonesia). The GNSS receiver in Kiruna is a $50 \mathrm{~Hz}$ Javad Legacy EGGD receiver which was installed in October 2004. A receiver of the same type was installed in Bandung and has been operational since December 2005. At Tenerife a $50 \mathrm{~Hz}$ Topcon Legacy EGGD+ receiver was installed at the end of August 2006 on the rooftop of a lighthouse in the harbour of Puerto de la Cruz de Tenerife. The raw data 
Table I. Monitoring activity of the institutions involved in the COST 296 community.

\begin{tabular}{|c|c|c|c|c|c|}
\hline Station & Coordinates & Samp. & Data interval & Data flow & Institution \\
\hline NyAlesund0 & $78.9 \mathrm{~N} 11.9 \mathrm{E}$ & $50 \mathrm{~Hz}$ & From Oct 2003 & ftp 15 min & INGV Rome \\
\hline NyAlesund1 & $78.9 \mathrm{~N} 11.8 \mathrm{E}$ & $50 \mathrm{~Hz}$ & From Nov 2006 & $\mathrm{ftp} 15 \mathrm{~min}$ & INGV Rome \\
\hline Longyearbyen & $78.1 \mathrm{~N} 16.0 \mathrm{E}$ & $50 \mathrm{~Hz}$ & From Nov 2006 & ftp 15 min & INGV Rome \\
\hline Hornsund1 & $77.0 \mathrm{~N} 15.0 \mathrm{E}$ & $50 \mathrm{~Hz}$ & From Sep 2007 & $\mathrm{ftp}$ & SRC - PAS Warsaw \\
\hline Hornsund2 & $77.0 \mathrm{~N} 15.0 \mathrm{E}$ & $50 \mathrm{~Hz}$ & From Sep 2007 & $\mathrm{ftp}$ & SRC - PAS Warsaw \\
\hline Hornsund3 & $77.0 \mathrm{~N} 15.0 \mathrm{E}$ & $50 \mathrm{~Hz}$ & From Sep 2007 & $\mathrm{ftp}$ & SRC - PAS Warsaw \\
\hline Bandung & $6.9 \mathrm{~S} 107.6 \mathrm{E}$ & $25 \mathrm{~Hz}$ & From Dec 2005 & DVD & DLR \\
\hline Kiruna & $67.8 \mathrm{~N} 20.4 \mathrm{E}$ & $50 \mathrm{~Hz}$ & From Oct 2004 & On line & DLR \\
\hline Puerto de la Cruz & $28.4 \mathrm{~N} 16.5 \mathrm{~W}$ & $50 \mathrm{~Hz}$ & From Sep 2006 & On line & DLR \\
\hline Trondheim & $63.4 \mathrm{~N} 10.4 \mathrm{E}$ & $50 \mathrm{~Hz}$ & From Dec 2007 & On line & IESSG - Un. Nottingham \\
\hline Nottingham & $52.9 \mathrm{~N} 1.2 \mathrm{~W}$ & $50 \mathrm{~Hz}$ & From Jun 2001 & ftp 15 min & IESSG - Un. Nottingham \\
\hline Warsaw & $52 \mathrm{~N} 21 \mathrm{E}$ & $50 \mathrm{~Hz}$ & From Sep 2007 & $\mathrm{ftp}$ & SRC - PAS Warsaw \\
\hline Dourbes & $50.1 \mathrm{~N} 4.6 \mathrm{E}$ & $50 \mathrm{~Hz}$ & From May 2006 & DVD & IESSG - Un. Nottingham \\
\hline El Arenosillo & $37.1 \mathrm{~N} 6.8 \mathrm{~W}$ & $50 \mathrm{~Hz}$ & In progress & ftp $15 \mathrm{~min}$ & INGV Rome \\
\hline Chania & $35.5 \mathrm{~N} 24.1 \mathrm{E}$ & $50 \mathrm{~Hz}$ & From Jun 2007 & ftp 15 min & INGV Rome \\
\hline Hue & $16.4 \mathrm{~N}, 107.6 \mathrm{E}$ & $50 \mathrm{~Hz}$ & From Jan 2006 & DVD & IETR Rennes \\
\hline HoChiMinh & $10.8 \mathrm{~N} 106.5 \mathrm{E}$ & $50 \mathrm{~Hz}$ & From Mar 2005 & DVD & IETR Rennes \\
\hline Douala & $3.7 \mathrm{~N} 9^{\circ} 7 \mathrm{E}$ & $50 \mathrm{~Hz}$ & $2004-2005$ & $\mathrm{CD}$ & ESA / ESTEC \\
\hline N'Djamena & $12.1^{\circ} \mathrm{N}, 15.07^{\circ} \mathrm{E}$ & $50 \mathrm{~Hz}$ & From Oct 2006 & $\mathrm{CD}$ & IEEA Paris \\
\hline Cayenne & $4.82^{\circ} \mathrm{N} 52.36 \mathrm{~W}$ & $50 \mathrm{~Hz}$ & From Jul 2006 & Daily ftp & CLS Toulouse \\
\hline BTN & 74.7S $164.1 \mathrm{E}$ & $50 \mathrm{~Hz}$ & From Jan 2006 & Daily ftp & INGV Rome \\
\hline DomeC & $75 \mathrm{~S} 123 \mathrm{E}$ & $50 \mathrm{~Hz}$ & From Jan 2008 & Daily ftp & INGV Rome \\
\hline
\end{tabular}

sampling rate for the receiver in Bandung is reduced to $25 \mathrm{~Hz}$ due to a limited internet bandwidth. The receiver in Tenerife is working in online mode with both, 25 or $50 \mathrm{~Hz}$. All raw data from Kiruna are acquired by $50 \mathrm{~Hz}$ in online mode. For steering processes of the sensors as well as the data exchange the so called Experi- mentation and Verification Network (EVnet) of DLR is used. EVnet is a near real-time network based on modular configurable and adaptable hardware and software components. The main functionality is to acquire and process GNSS signals as well as corresponding environmental information. The network structure of the 
EVnet implies the possibility to provide these data to internal and external users of the network by specific services. Because the $\mathrm{Javad} / \mathrm{Topcon}$ receivers at real time sensor stations are not be able to deliver scintillation based data directly (in comparison to GSV 4004 receiver that contains specific firmware to do this) specific software tools were developed by DLR and GMV to convert binary data into an ASCII data stream and to compute scintillation values based on the input values coming from the Javad/Topcon receivers.

SRC has installed three GISTM receiver at the Polish Polar Station (PPS) sited in the region of the Hornsund Bay in southern Spitsbergen $\left(77.00^{\circ} \mathrm{N}, 15.55^{\circ} \mathrm{E}\right.$, CGM latitude $74.11^{\circ}$ N) (Wernik et al., 2008). This location allows study of the ionosphere, depending on the local time and magnetic activity, in the auroral zone, dayside cusp and polar cap regions. The three antennae and GISTM receivers are installed at the nodes of the right-angle triangle with the legs 93 and $98 \mathrm{~m}$ long. One of the legs is parallel to the geographic meridian. Note that the magnetic declination in Hornsund is small $\left(+3.1^{\circ} \mathrm{CGM}\right)$ therefore the geographic meridian almost coincides with the magnetic meridian. Raw data from all three receivers are stored on a hard disc with a capacity of 500 GB. This is sufficient to store more than a year of data. Software supplied with the receivers performs detrending of phase and amplitude data. From the detrended signal various statistical parameters are derived, which together with a number of utility parameters are output every minute and transmitted via satellite Internet to the Space Research Center (SRC) in Warsaw. Since October 2007 the post-processed data have been available on the web. Spaced-receiver scintillation technique has been used for decades to measure the drift, orientation and shape of irregularities, and the height of the irregularity layer. Numerous measurements have been carried out in the equatorial and high latitude regions, using radio transmissions from low orbiting and geostationary satellites (e.g. Livingston et al., 1982; Rino and Livingston, 1982; Wernik et al., 1983; Costa et al., 1988; Basu et al., 1991; Bhattacharyya et al., 2001; Tiwari et al., 2006). It should be noted that low orbiting satellites are more appropriate for providing information on the anisotropy of irregularities. In this case, it is difficult to derive the irregularity drift velocity from the measured drift of the diffraction pattern controlled mainly by the fast satellite motion.

The quasi-stationary GPS satellites offer an opportunity for continuous monitoring of ionospheric drifts and irregularity anisotropy using inexpensive equipment. Most GPS-based measurements have been made at low latitudes to estimate the ionospheric zonal irregularity velocities (e.g. Kil et al., 2000; Kintner et al., 2001; 2004; Ledvina et al., 2004; Otsuka, 2006).

The Institute of Engineering Surveying and Space Geodesy (IESSG) of the University of Nottingham pioneered GPS ionospheric scintillation monitoring in Europe with GISTM receivers. Between June 2001 and December 2003 four units were installed at stations in the UK and Norway, covering geographic latitudes from $53^{\circ} \mathrm{N}$ to $70^{\circ} \mathrm{N}$ approximately. That project was funded by the Engineering and Physical Sciences Research Council (EPSRC) in the UK and extensive ionospheric scintillation and TEC data were collected and analysed. Due to operational limitations no high rate data was stored and analyses were based solely on the ionospheric scintillation indices, focusing on statistical analyses and impact for GNSS users (Rodrigues et al., 2004; Aquino et al., 2005a; 2005b). These units were deactivated in 2004 and were later redeployed at Nottingham $\left(52.90^{\circ} \mathrm{N}, 1.20^{\circ} \mathrm{W}\right)$, Dourbes $\left(50.10^{\circ} \mathrm{N}, 4.60^{\circ} \mathrm{E}\right.$, in collaboration with the Royal Meteorological Institute of Belgium) and Trondheim $\left(63.40^{\circ} \mathrm{N}, 10.40^{\circ} \mathrm{E}\right)$, where currently high rate $(50 \mathrm{~Hz})$ data as well as scintillation parameters are being recorded (please refer to the table below). Associated with all data collected by the IESSG, range data that can be converted to the RINEX (Receiver INdependent EXchange) format has also been recorded.

\section{The modelling activity}

\subsection{GISM phase screen model}

IEEA has developed the GISM model which is a mixed climatological/physical model. It 

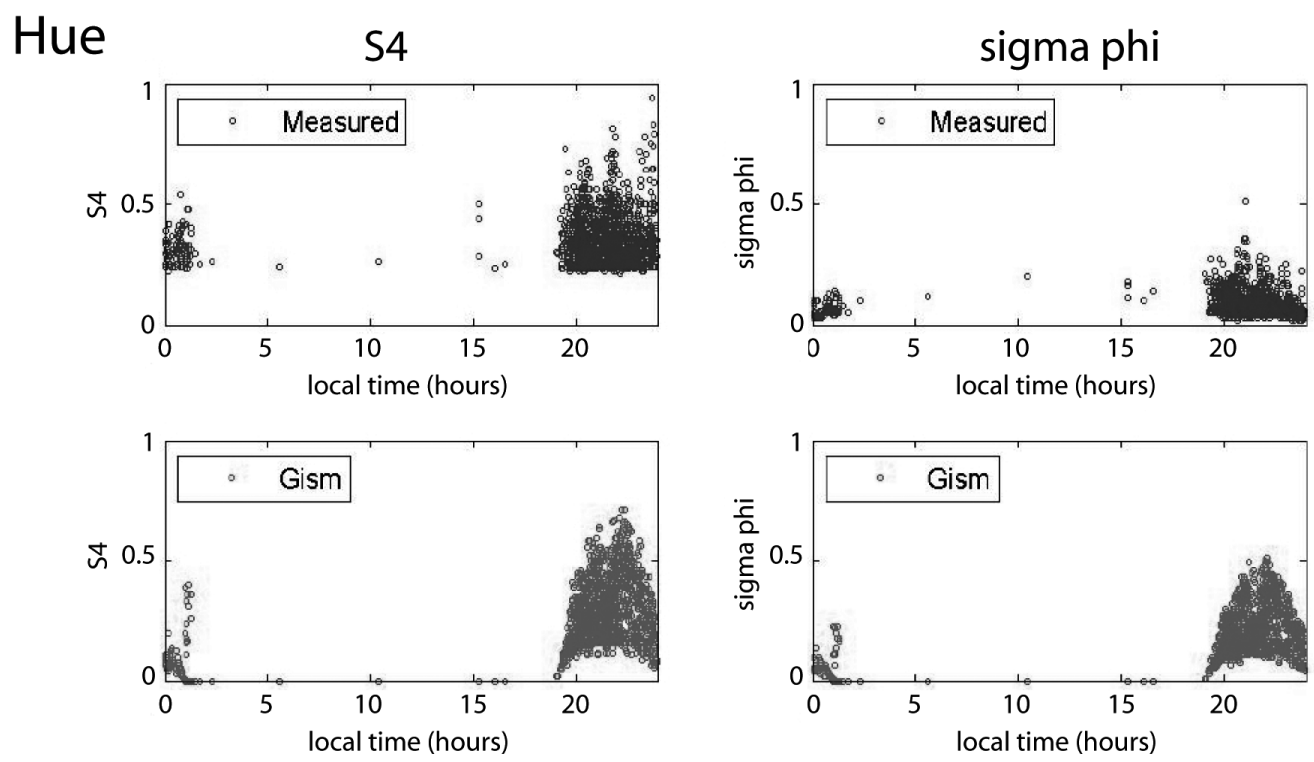

Fig. 7. Model-measurements comparisons (PRIS measurement campaign 2006-2007).
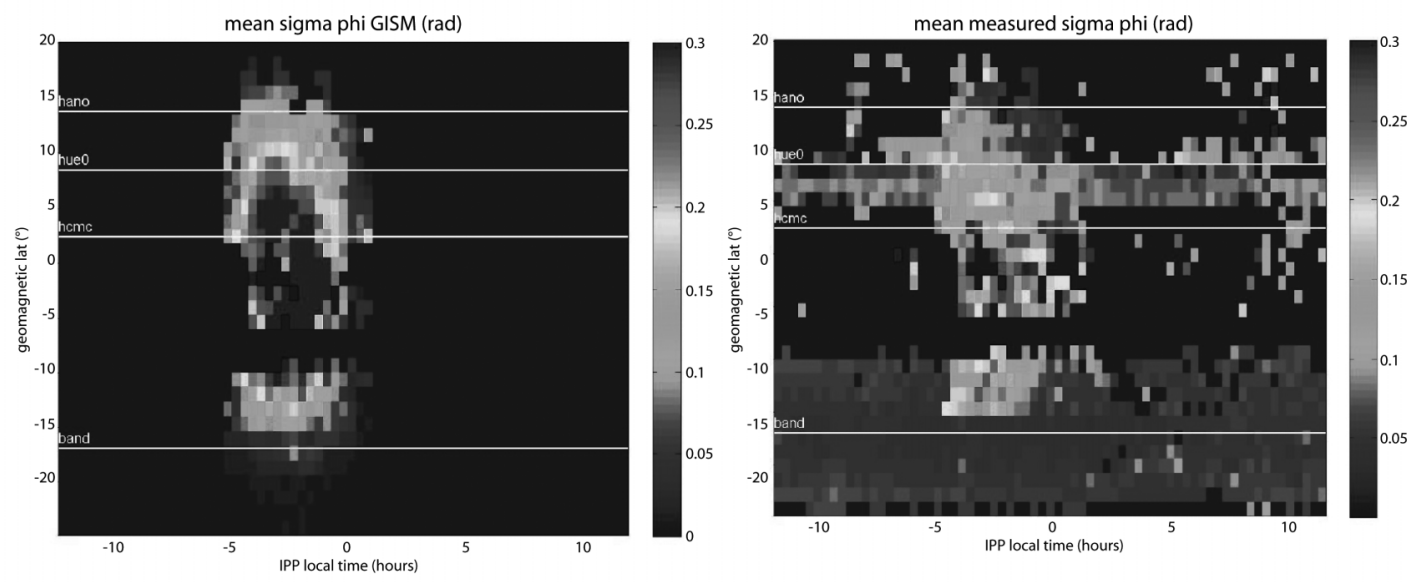

Fig. 8. Comparisons model-measurements in Vietnam and Indonesia.

calculates mean errors and scintillations due to propagation through the ionosphere (Béniguel, 2002). Mean errors are obtained by a ray technique using the values of the ionosphere electronic density. This last is obtained with NeQuick model which is included in GISM.
The line of sight being determined, the fluctuations are calculated in a second stage using a multiple phase screen technique.

The standard deviations of intensity $\left(S_{4}\right)$ and phase (sigma phi) at ground level are calculated. GISM model allows considering either a 

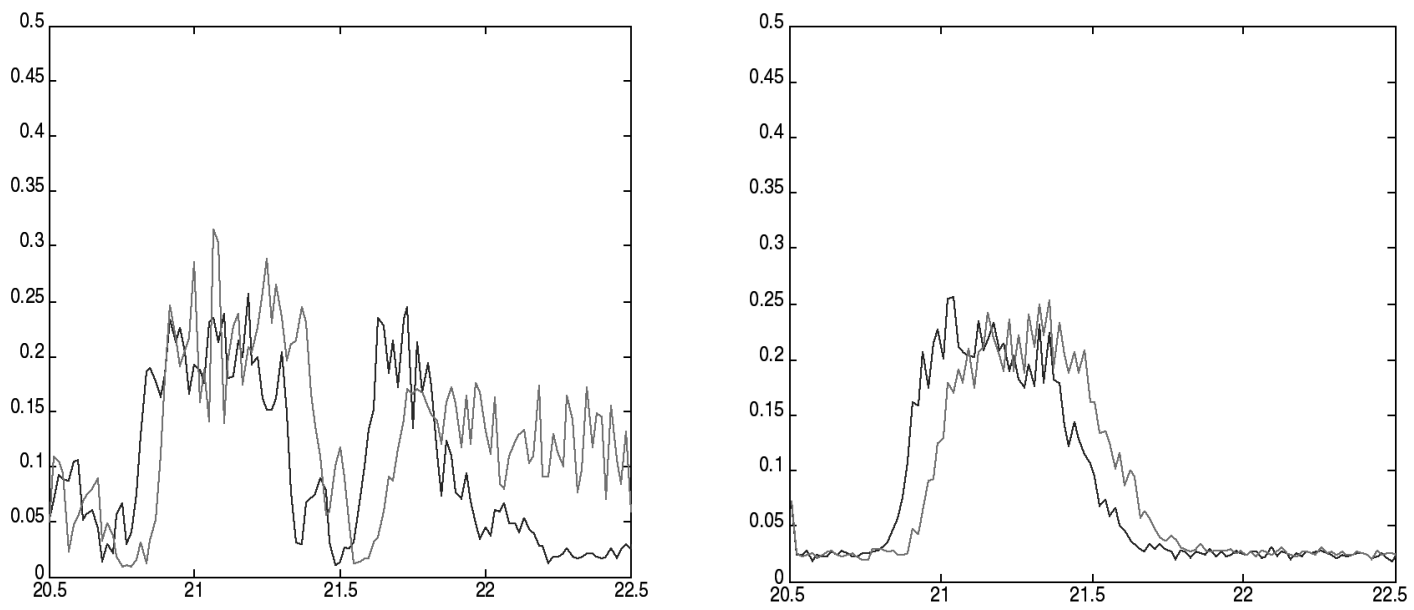

Fig. 9. Measurement vs modelling for propagation through a bubble.

trajectory described by a list of successive points or a constellation (GPS, Galileo or Glonass). An orbit generator has been introduced for this capability. The input in that case is the Yuma file. GISM also produces scintillation maps as presented on the left panel of fig. 8 . Figure 7 below shows a comparison of measurements and modeling in Vietnam during the two years of the PRIS measurement campaign.

Four receivers were located in Vietnam and Indonesia, practically at the same longitude. The measurements recorded have been put on the same plot (cf. fig. 8). It shows the global pattern. The horizontal stripes between $-25^{\circ}$ and $-10^{\circ}$ and between $4^{\circ}$ and $10^{\circ}$ correspond to the multi-paths in Hanoï and Bandung. The modelling results obtained with GISM model (v. 6.45) are given for comparison and show a reasonable agreement.

\subsection{Hybrid scintillation propagation model}

Throughout the duration of the COST 296 Action, the St. Petersburg-Leeds team worked to develop its own scintillation propagation model for transionospheric paths of propagation. The initial version of this model, valid for the case of smoothly inhomogeneous background ionosphere (but not containing mid- scale local inhomogeneities), is particularly appropriate for describing a wide variety of situations, including the case of strong scintillation and values of the fractional electron density up to $100 \%$ for operating frequencies of $1 \mathrm{GHz}$ and above (Gherm et al., 2005a). (Some additional material clarifying the content of this paper can also be found in the companion paper Gherm $e t$ $a l ., 2005 b)$. This is found to be possible because, according to our estimates, at this range of frequencies the regime of strong scintillation never occurs inside the ionospheric layer. Therefore, the perturbation theory can be employed to describe the propagation in the ionosphere and then the field immediately below the ionosphere can be determined. Since strong scintillation may well occur for propagation below the ionosphere, to convey the field calculated for the level located immediately below the ionosphere down to the Earth's surface, the general theory of the random screen is employed. We term this approach the hybrid scintillation propagation model. Different scintillation effects have been described and assessed within the range of validity of the developed model and these results were presented at a number of workshops and international conferences (Gherm et al., 2006, 2007a,b; Strangeways et al., 2006).

Recently the hybrid model has been further 
extended to enable a description of the propagation effects due to local mid-scale (meso-scale) ionospheric inhomogeneities, e.g. bubbles of the low-latitude ionosphere, or patches at high latitudes. The effects for these cases differ essentially from effects in the mid-latitude ionosphere because of the occurrence of the moving local inhomogeneities which make the stochastic signal essentially statistically non-homogeneous. Because of this, the hybrid propagation model has been significantly modified to account for the effects arising in statistically nonstationary conditions. The extended method has enabled modelling of a number of scintillation effects typical for the high-latitude and low-latitude ionospheres. The effects due to bubbles of the equatorial ionosphere were described and presented in Gherm et al., 2007c,d,e; Strangeways et al., 2007a,b and Zernov et al., 2008a,b and possible scintillation effects due to patches in the polar ionosphere were described in Maurits et al., 2008 and Zernov et al., 2008a,b.

A very good agreement was achieved between the experimental data of the scintillation effects due to bubbles and the results of modelling for the same receiver, location, time and conditions. To illustrate this, the two panels in fig. 9 (from Zernov et al., 2008b) presented below show the experimental results for the scintillation index $S_{4}$ (courtesy of Dr. B. ArbesserRastburg, ESA-ESTEC) and the results of simulation of the enhancement of $\mathrm{S}_{4}$ caused by a bubble observed at Douala, Cameroon $\left(4^{\circ} 0^{\prime} \mathrm{N}\right.$, $9^{\circ} 42^{\prime} \mathrm{E}$ ). The variation of the $\mathrm{S}_{4}$ scintillation index is shown for the received signal from two different satellites of the GPS constellation PRN26 (blue) and PRN29 (green) visible on 7 June 2004 at Douala, Cameroon in the period from $20.5 \mathrm{~h}$ to $21.5 \mathrm{~h}$. In the left panel the experimentally measured time dependence of the scintillation index $S_{4}$ is presented. The most pronounced peak of scintillation in both curves corresponds to a time period around 21:00. For this time the elevation angles of the satellites are $75^{\circ}$ and $80^{\circ}$. The results of modeling these events in the framework of a single bubble scintillation propagation model are shown in the right panel. A fairly good correspondence of the theory to the experimental results is observed, including values of $S_{4}$, time of start and finish, and relative delays of the scintillation patterns for the two satellites.

The comprehensive description of the range of possible applications of the extended St. Petersburg-Leeds scintillation propagation model was given in the presentation Zernov et al. (2008b) at the IES2008 at Alexandria, Virginia, USA in May, 2008.

In conclusion, a fairly advanced scintillation propagation model for transionospheric paths of propagation has been developed, capable of describing a wide variety of the ionospheric conditions of propagation and geometry. It is valid for a range of frequencies where the regime of strong fluctuations does not occur inside the inhomogeneous ionospheric layer. The model accounts for both quasi-regular and random ionospheric structures including the most complicated situations of the low-latitude ionosphere (bubbles) and high-latitude ionosphere (patches, blobs, etc.). It generates random time series of a received signal and determines its statistical moments (power spectra, correlation functions, scintillation index, etc.). All this comprises the basis for the simulation of the stochastic signals on transionospheric paths of propagation.

\subsection{Amplitude radio scintillation model}

The climatological model of amplitude radio scintillation Wernik-Alfonsi-Materassi (WAM) was presented in 2005 in the publication Wernik et al. (2007) (see also Wernik et al. (2004)), and discussed extensively within the COST community during the workshop «Ionospheric scintillation: scientific aspects, space weather application and services, from 20 to 22 February 2008 at the University of Nottingham, with the talk Materassi et al. (2008).

The WAM model is a model of radio scintillation in which the action of the irregular ionosphere on the radio signal is mimicked via a phase screen. The statistics of this phase screen is constructed analyzing the in situ data of fluctuations $\mathrm{D} N$ of the ionization density as measured by the satellite Dynamics Explorer 2 (DE2). The assortment of helio-geophysical conditions covered by the three years of mission of the DE-2 determines the climatological charac- 


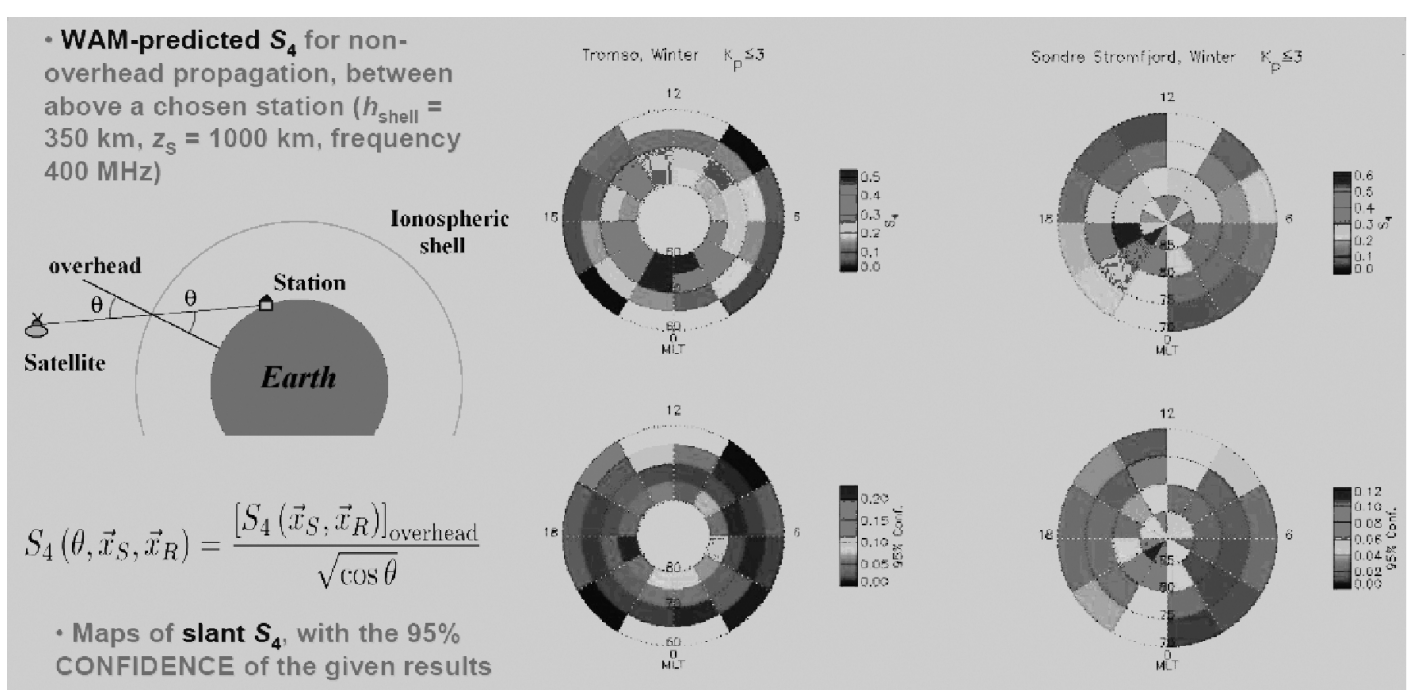

Fig. 10. An example of the prediction possible via the WAM model, giving the amplitude scintillation index within the field of view of an assigned station for certain helio-geophysical conditions.

ter of the WAM model. As far as the background ionosphere $N_{0}$ is concerned, the IRI-95 model has been adopted, with corrections for the topside where the values of $N_{0}$ given by IRI95 are clearly unreliable (e.g. at very high latitudes).

The WAM model is able to predict the value of the index $S_{4}$ along an assigned radio link, given the helio-geophysical conditions of this link: in its present version, WAM classifies the different helio-geophysical conditions according to the only parameter $K_{\mathrm{p}}$. The WAM model also predicts the confidence with which the values of $S_{4}$ given should be intended.

Figure 10 reports the results of the WAM prediction for the radio links from GPS satellites down to Troms $\varnothing$ and Sondre Stromfjord, in winter conditions for $K_{p} \leq 3$ : this is an example of how the model works.

The validation of the model has been initiated and has already given encouraging results, as one can see from fig. 11, where the behavior of $S_{4}$ as a function of the UT constructed by the WAM model is compared with the one of real data, as reported in the paper quoted in the figure.

\subsection{Trans Ionospheric propagation simulator}

Measurements of scintillation on radar target returns were made using the ALTAIR satellitetracking radar on Kwajalein Island $\left(9.4^{\circ} \mathrm{N}\right.$, $166.8^{\circ} \mathrm{E}$ ) during 2005/6 (Cannon et al., 2006). The radar tracked low earth orbiting (LEO) calibration spheres of uniform radar cross section (RCS) using chirp waveforms at $158 \mathrm{MHz}$ (7 $\mathrm{MHz}$ bandwidth) and $422 \mathrm{MHz}(18 \mathrm{MHz}$ bandwidth) with a pulse repetition frequency (PRF) of around $285 \mathrm{~Hz}$. The complex impulse responses were recorded for contiguous sequences of 1024 chirp returns and by taking a Fourier transform in each range cell (group delay bin) each 3.6-second sequence was presented as a single channel scattering function (CSF) which mapped the power of the radar returns against both the group delay and the Doppler frequency. The $S_{4}$ index was also measured from 10 -second intervals of RCS measurements. Under conditions of strong scintillation (high $S_{4}$ ) the CSF exhibited a «parabolic» spread of the power towards increasing excess delay with increasing positive or negative Doppler (see example in figs. 12a and b) (Rogers et al., 2008). 

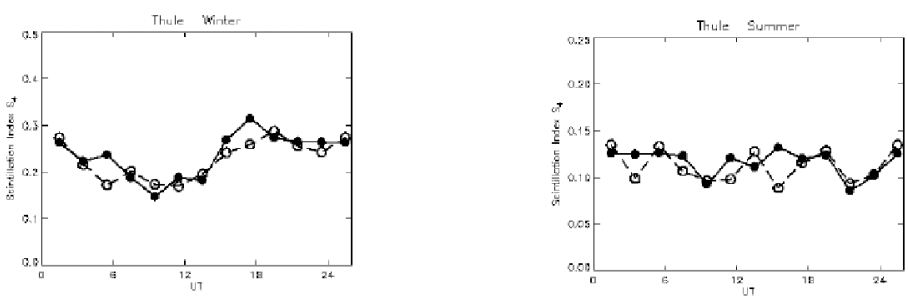

- WAM-predicted $S_{4}$ compared with the real data as a function of UT: good agreement with the results by Basu et al., (continuous line $K_{\mathrm{p}} \leq 3$, dashed lines $K_{\mathrm{p}}>3$.
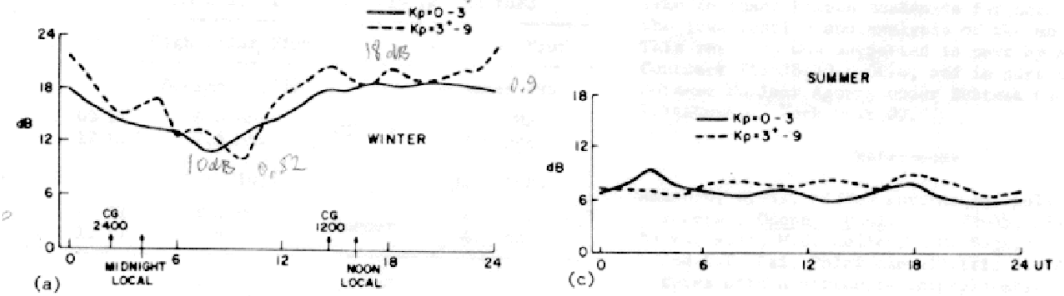

Fig. 11. A preliminary validation study for the model WAM, in which the values of the $S_{4}$ index predicted by it are compared with those from real data reported in the paper Su. Basu et al., Radio Sci., v. 20, 347,1985 quoted.
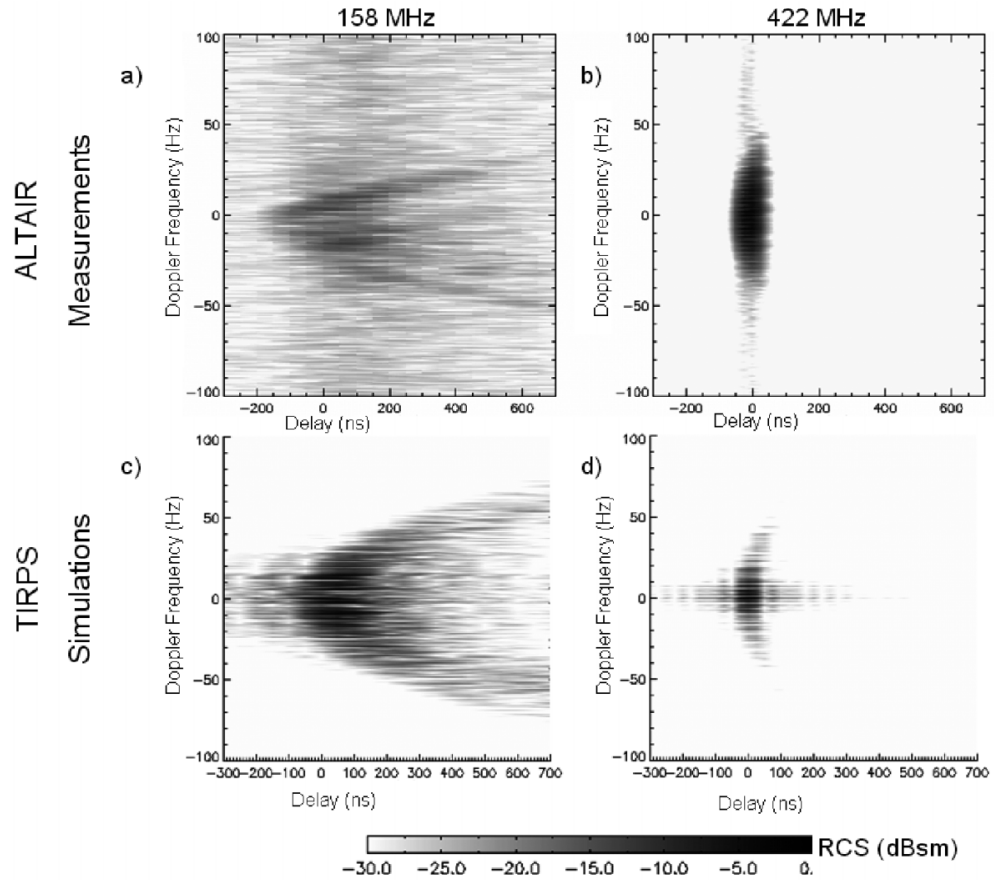

Fig. 12. Channel Scattering Functions of ALTAIR radar returns from a calibration sphere at 10:06 UT on 18 January 2005 at (a) $158 \mathrm{MHz}$ and b) $422 \mathrm{MHz}$. Corresponding TIRPS predictions (normalised to $0 \mathrm{~dB}^{2}$ ) are shown for c) $158 \mathrm{MHz}$ and d) $422 \mathrm{MHz}$, appropriate to a $\mathrm{PRF}=262 \mathrm{~Hz}$, elevation $\theta=24^{\circ}$, azimuth $=9^{\circ}$, $C_{k} \operatorname{Lsec}(\theta)=10^{35}, v_{\text {eff }}=1604 \mathrm{~ms}^{-1}, \mathrm{p}=2.5$ and $L_{o}=10 \mathrm{~km}$. 
This effect was more pronounced for the lowerfrequency waveform $(158 \mathrm{MHz})$.

To simulate these radar measurements Rogers et al. (2008) developed a thin phase screen, splitstep Parabolic Equation technique called the Trans-Ionospheric Radio Propagation Simulator (TIRPS). The spectrum of the phase screen was a function of three variables: the integrated strength of turbulence, $C_{k} L$; the spectral index, $p$; and the outer scale, $L_{o}$. TIRPS reproduced the observed parabolic spreading of the power in the CSF under conditions of high $C_{k} L$ (see example figs. 1c and d) and it was demonstrated that a lower value of $p$ (representing greater power in the smaller-scale irregularities) produced a greater distribution of power into the parabolic «horns» of the CSF, presumably as a result of stronger forward scattering by small-scale irregularities. The Doppler separation of the CSF horns increased with higher effective scan velocity of the ionospheric pierce point, $v_{\text {eff }}$ (as defined by Rino (1982).

Rogers et al. (2008) calculated the delay and Doppler spreads from the measured and simulated CSFs and determined the coherence bandwidth (CB) and coherence time (CT) respectively from the reciprocals of these spreads. The measured coherence times (CT) decreased exponentially with $S_{4}(422 \mathrm{MHz})$ and, up to an $S_{4}$ of 2.2 (indicative of Rayleigh fading on a correlated two-way channel), the TIRPS simulations matched this trend using a phase screen with $p=3$. A higher spectral index $(p=4)$ was required to simulate the CTs observed for $S_{4}$ higher than 2.2 ; this represents strong focusing conditions. There was a general decrease in CT for higher values of $v_{\text {eff }}$ and the simulations provided a good fit to the CT trend with $S_{4}$ where an appropriate value of $v_{\text {eff }}$ was used in the simulation. These results showed that with an appropriate choice of phase screen parameters, the TIRPS simulator could be used to assist the design and operation of trans-ionospheric radars performing coherent pulse integration.

\section{Advances in scintillation studies}

\subsection{Wavelet Analysis}

Considering that radio scintillation is a nonstationary phenomenon which is better de- scribed locally than globally with time, the choice of analyzing amplitude scintillation via continuous and discrete wavelets was made.

Both the continuous and the discrete wavelet analyses (CWA and DWA) have been tried on amplitude scintillation studies, for two different purposes. CWA is useful to produce very eloquent scalograms where the energy distribution of the signal, as a function of the time scale, is seen to evolve with time. This visualization allows the location and study of the major singularities and inter-scale processes of the radio scintillation. Figure 13 reports a typical scalogram. First of all, the time-behavior of the signal may be studied as depending on the time scale: on the average, smooth features between $100 \mathrm{~s}$ and $1000 \mathrm{~s}$ may be considered the remnants of the initial «trend» of the signal, features between $0.4 \mathrm{~s}$ and $100 \mathrm{~s}$ are likely to contain the full information on the turbulence of the medium, while features below the $0.4 \mathrm{~s}$ should be pure (instrumental) noise. It is however remarkable that these scale bands may depend on time: the «turbulent» region elongates down to scales as small as $0.1 \mathrm{~s}$ in correspondence of big bursts, for instance at about 13' from the beginning of the time series reported.

Another interesting visualization allowed for by CWA is to single out periodic features of non-geophysical origin, like unwanted intersatellite interference or multipath. This is the example reported in fig. 14 (Materassi, 2008), where the «U-features» along the same link are repeating themselves day after day with a sideral day periodicity, and are likely to be due to such non-geophysical effects.

The usefulness of DWA is instead mainly in filtering, i.e. denoising and detrending the signal. Considering the three-band structure discussed for fig. 13, the extraction of the part of the signal containing the most turbulence information might be done by filtering out the smoothest part and the noisiest part of the scalogram. This could be done in principle via Fourier band filtering, but discrete wavelet band filtering is preferred because it better fits such a time-varying signal. In the paper (Materassi et al., 2009) the average continuous wavelet power is calculated using three different detrending techniques, as a function of the time scale. 


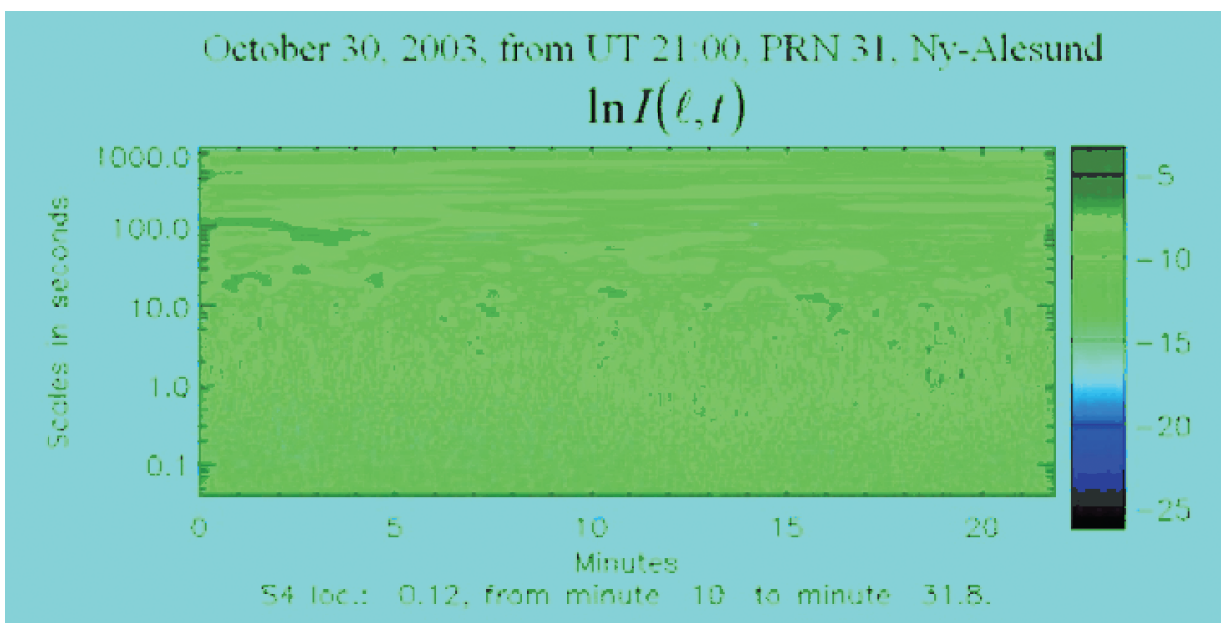

Fig. 13. An example of scalogram from CWA for amplitude scintillation signals.

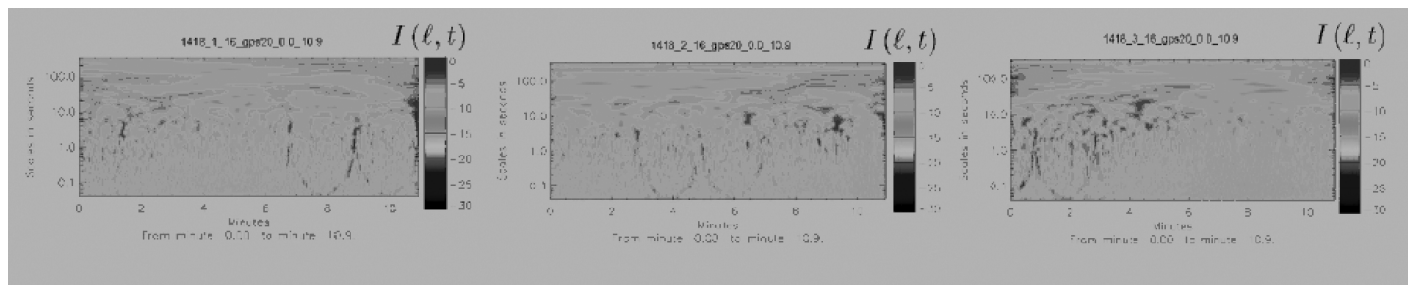

Fig. 14. Sideral-periodic features in a scalogram, probably of non-geophysical origin.

Then, scale by scale the spread $\Sigma(l)$ of these values is calculated and plotted, as in fig. 15 .

The threshold scale $l_{1 / 2}$ defines the scale at which the relative spread becomes equal to 0.5 . Results like those in fig. 15 lead the authors of (Materassi et al., 2007) to assess that the probably best way of selecting the part of the signal encoding the information on the turbulent medium is to filter it via DWA within a time scale band $\left[l_{\min }, l_{\max }\right]: l_{\min } \cong 0.02 \mathrm{~s}$ and $l_{\max }$ is between $20 \mathrm{~s}$ and $30 \mathrm{~s}$. Below $l_{\min }$ one has essentially noise of probably instrumental origin, and above $l_{\max }$ the features are given by the regular behavior of the ionosphere on large scales, hence non interesting for turbulence analysis.

Taking advantage of data collected using the same type of instruments (i.e. GISTM receivers), the Istituto Nazionale di Geofisica e Vulcanologia (INGV) and the Institute of Engineering Surveying and Space Geodesy (IESSG) of the University of Nottingham are cooperating to perform statistical studies on their data acquired at cusp, auroral and middle latitudes. The behaviour of the scintillation occurrence as a function of the magnetic local time and of the corrected magnetic latitude is under investigation to characterize the scintillation climatology. The aim of this type of analysis is, once developed over a robust data set, to provide information useful for the development of nowcasting and forecasting algorithms. The first results of the analysis confirm that the scintillations occur primarily during the equinoxes and around magnetic noon and midnight, but also reveal interesting features in- 


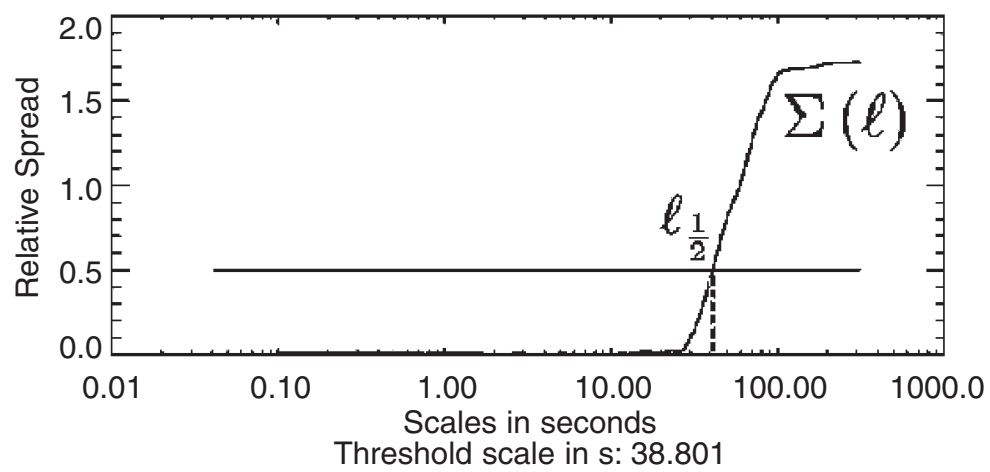

Fig. 15. The relative spread of the average continuous wavelet power as a function of time scale, among the amplitude scintillation signals detrended in three different ways (see Materassi et al., 2007).

dicating some MLT sectors not being affected by scintillation events (Spogli et al., 2009). Other statistical studies made by comparing the backscattered echoes acquired by the CUTLASS radars of the SuperDARN (SD) chain and the scintillation measurements over Ny Alesund have demonstrated that it is possible to reveal signatures of the cusp position by looking at the correspondence (in MLT and MLat) between the SD backscattering and the enhancement of the scintillation activity (Coco et al., 2007).

\subsection{High latitude scintillations}

Work at the IESSG, by Rodrigues et al. (2004) and Aquino et al. (2005a), was aimed at characterising the occurrence and magnitude of scintillations over Northern Europe based on a long-term data set of scintillation indices (2001-2003). Figure 16 (from Aquino et al., 2005a) shows the curves of the complement of the cumulative frequency of occurrence of phase and amplitude scintillation values for station Bronnoysund $\left(\sim 65^{\circ} \mathrm{N}\right)$ for all days of 2003 , for elevation angles over $15^{\circ}$ [phase and amplitude scintillation are represented respectively by the indices $\sigma_{\phi}$ and $S_{4}$ ]. The curves are presented in 3-hour time bins, to enable correlation analyses with the 3 -hour $\mathrm{Kp}$. The right plot shows that values of $S_{4}>0.5$ barely occurred in Bronnoysund, whereas occurrence of $\sigma_{\phi}>0.5$ was significantly higher (left plot), with values reaching $5 \%$ of the time on many days, especially during the night time sectors. Similar analyses at Hammerfest $\left(\sim 71^{\circ} \mathrm{N}\right)$ show that occurrence of $S_{4}>0.5$ very rarely exceeded $1 \%$ on any particular day of 2003. However, as at Bronnoysund, occurrence of $\sigma_{\phi}>0.5$ at Hammerfest reached over $5 \%$ on many days. Analyses carried out for Nottingham $\left(\sim 53^{\circ} \mathrm{N}\right)$ and Bergen $\left(\sim 60^{\circ} \mathrm{N}\right)$, showed significantly lower probabilities. Figure 17 shows the correlation of the maximum daily occurrence of $\sigma_{\phi}>0.5$ for 3 -hour time bins with the maximum daily value of $K_{\mathrm{p}}$ for every day of 2002 (left) and 2003 (right) at Bronnoysund. Correlation is observed at Bronnoysund, in particular during 2003, when a greater number of $K_{\mathrm{p}}>6$ occurred. Further details of these analyses can be found in Aquino et al. (2005a).

In the interest of GPS applications requiring high levels of availability, long-term analyses were conducted at the IESSG on the probability of a number of GPS satellites simultaneously observing high levels of phase scintillation (Rodrigues et al., 2004 and Aquino et al., 2005a). The aim was to assess the threat this would represent in case a certain level of phase scintillation leads to loss of satellite lock. It was found that there was a probability of about $0.1 \%$ of 2 satellites being simultaneously affected by $\sigma_{\phi}$ $>0.5$, when all of the 2002 scintillation data for Hammerfest was analysed. When the 2003 data 

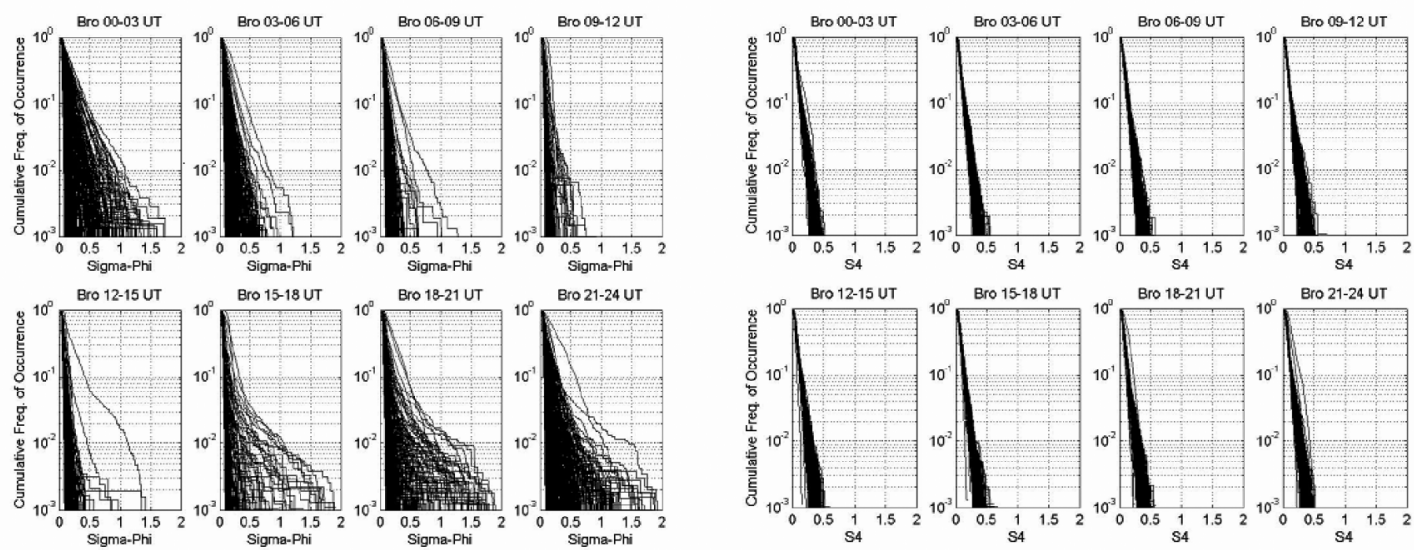

Fig. 16. Cumulative frequency of occurrence of phase and amplitude scintillation values for station Bronnoysund $\left(\sim 65^{\circ} \mathrm{N}\right)$ for year 2003 .

is analysed a probability of about $0.25 \%$ of 2 satellites being simultaneously affected by $\sigma_{\phi}>0.5$ was observed, amounting to about 22 hours within the one year period. Similar analysis carried out for a 2-day period under severe geomagnetic conditions, during October 29th and 30th, 2003 , shows a probability of about $3 \%$ of 2 satellites observing $\sigma_{\phi}>0.5$ simultaneously. In fact, under such severe conditions there was a probability of $1 \%$ of 3 satellites observing $\sigma_{\phi}>0.5$ simultaneously. Critically, over the 2-day period, $1 \%$ represents 30 minutes in absolute terms, a figure of concern for safety-critical applications if these levels of phase scintillation lead to loss of satellite lock. More discussion on this is found on the references above.

\section{A different scintillation index for high latitudes}

Data from the GPS scintillation monitor based on $50 \mathrm{~Hz}$ measurements recorded at Dirigibile Italia Station (Ny-Alesund, Svalbard) are used to investigate on the possible adoption of an alternative parameter for the estimate of phase fluctuations. This parameter is defined as the standard deviation of the phase rate of change (Forte B., 2005):

$$
S_{\phi}=\sqrt{\left\langle\left(\frac{\partial \phi}{\partial t}\right)^{2}\right\rangle}
$$

The selected time intervals refer to 2007 and are related to disturbed conditions $(-70 \mathrm{nT}<$ Dst $<-40 \mathrm{nT}, \mathrm{Kp}>4$ ) and to different seasons (table II). After selection and visualisation by means of the web tool provided by the INGV (Romano et al., 2008), the indices were been calculated by using raw data directly. Some representative events are also shown in fig. 18 where the scintillation indices, $S_{4}, \sigma_{\phi}$, and $S_{\phi}$ are calculated by means of a sixth order Butterworth filter (similar to what routinely done by the scintillation monitor) for three different detrending conditions: $0.1 \mathrm{~Hz}$ (solid line), $0.3 \mathrm{~Hz}$ (dotted line), and $0.5 \mathrm{~Hz}$ (dashed line) (Forte B., 2005). Also, the rate of change of TEC (TECu/min) is calculated when both $L 1$ and $L 2$ are on lock: data gaps in the rate of change of TEC are due to a loss of lock on $L 2$. As one can see from table II, $\sigma_{\phi}$ may reach large values (around 1 radian) during particularly disturbed conditions. Large values of $\sigma_{\phi}$ are measured by a larger number of satellites during disturbed conditions. The increase in the classical phase scintillation index $\sigma_{\phi}$ corresponds to an increase in TEC fluctuations. Nevertheless, during these events $S_{\phi}$ and $S_{4}$ have an almost constant behaviour with values always below a given threshold. Although both $S_{4}$ and $S_{\phi}$ show some slight modifications when the detrending cut-off frequency is changed, the phase scintillation index 
Table II. All the events analysed in 2007. The $\sigma_{\phi}$ values are divided into intervals, according to the phase scintillation levels that occurred on a particular day. The PRN column shows the number of satellites which measured a $\sigma_{\phi}$ in a given range and during a given UT period (UT column) for that particular day. Corresponding values for TEC fluctuations, $\mathrm{S}_{\phi}$ and $S_{4}$ are given in separate columns.

\begin{tabular}{|c|c|c|c|c|c|c|}
\hline Day & $\begin{array}{c}\text { Phase } \\
\text { Scintillation }\end{array}$ & PRN & UT & $\begin{array}{c}\triangle T E C / \triangle t \\
(\mathrm{TECu} / \mathrm{min})\end{array}$ & $\begin{array}{c}S_{\phi} \\
(\mathrm{rad} / \mathrm{s})\end{array}$ & $S_{4}$ \\
\hline 2007-01-28 & $\sigma_{\phi}<0.3$ & all & $00-24$ & $<0.5$ & $<2$ & $<0.2$ \\
\hline 2007-01-29 & $\begin{array}{l}0.3<\sigma_{\phi}<0.6 \\
0.6<\sigma_{\phi}<0.9\end{array}$ & $\begin{array}{l}8 \\
2\end{array}$ & $\begin{array}{c}12-13 ; 18-19 \\
21-00\end{array}$ & $\begin{array}{c}<1 \\
<1.5 \div 2\end{array}$ & $<2$ & $<0.2$ \\
\hline 2007-01-30 & $\begin{array}{l}0.3<\sigma_{\phi}<0.6 \\
0.6<\sigma_{\phi}<0.9 \\
0.9<\sigma_{\phi}<1.2\end{array}$ & $\begin{array}{l}10 \\
5 \\
2\end{array}$ & $\begin{array}{c}06-12 ; 21-23 \\
20-00 \\
07-08 ; 18-19\end{array}$ & $\begin{array}{l}<1 \\
<1.5 \div 2 \\
<2 \div 3\end{array}$ & $<2$ & $<0.2$ \\
\hline $2007-05-22$ & $\begin{array}{l}0.3<\sigma_{\phi}<0.6 \\
0.6<\sigma_{\phi}<0.9 \\
0.9<\sigma_{\phi}<1.2\end{array}$ & $\begin{array}{l}7 \\
3 \\
3\end{array}$ & $\begin{array}{l}09-16 ; 21-22 \\
12-16 ; 19-20 \\
12-15 ; 19-20\end{array}$ & $\begin{array}{l}<1 \\
<1.5 \div 2 \\
<2 \div 3\end{array}$ & $<2$ & $<0.2$ \\
\hline $2007-05-23$ & $\begin{array}{l}0.3<\sigma_{\phi}<0.6 \\
0.6<\sigma_{\phi}<0.9 \\
0.9<\sigma_{\phi}<1.2\end{array}$ & $\begin{array}{l}4 \\
2 \\
1\end{array}$ & $\begin{array}{c}06-09 ; 19-20 \\
23-00 \\
19-20\end{array}$ & $\begin{array}{l}<1 \\
<1.5 \div 2 \\
<2 \div 3\end{array}$ & $<2$ & $<0.2$ \\
\hline 2007-05-24 & $\begin{array}{l}0.3<\sigma_{\phi}<0.6 \\
0.6<\sigma_{\phi}<0.9 \\
0.9<\sigma_{\phi}<1.2\end{array}$ & $\begin{array}{l}9 \\
5 \\
1\end{array}$ & $\begin{array}{c}07-09 ; 11-13 ; 16-17 ; 21-22 \\
103-05 ; 06-08 ; 09-13 ; 16-18 \\
06-09\end{array}$ & $\begin{array}{l}<1 \\
<1.5 \div 2 \\
<2 \div 3\end{array}$ & $<2$ & $<0.2$ \\
\hline $2007-11-20$ & $\begin{array}{l}0.3<\sigma_{\phi}<0.6 \\
0.6<\sigma_{\phi}<0.9\end{array}$ & $\begin{array}{l}7 \\
3\end{array}$ & $\begin{array}{l}07-10 ; 20-21 \\
07-09 ; 09-11\end{array}$ & $\begin{array}{c}<1 \\
<1.5 \div 2\end{array}$ & $<2$ & $<0.2$ \\
\hline $2007-11-21$ & $\begin{array}{l}0.3<\sigma_{\phi}<0.6 \\
0.6<\sigma_{\phi}<0.9\end{array}$ & $\begin{array}{l}7 \\
2\end{array}$ & $\begin{array}{c}04-08 ; 09-10 ; 20-21 \\
04-06 ; 20-21\end{array}$ & $\begin{array}{c}<1 \\
<1.5 \div 2\end{array}$ & $<2$ & $<0.2$ \\
\hline $2007-11-22$ & $0.3<\sigma_{\phi}<0.6$ & 10 & 06-07; 08-14; & $<1$ & $<2$ & $<0.2$ \\
\hline
\end{tabular}

$\sigma_{\phi}$ appears to be critically dependent on this. In all the case studies here considered, $\sigma_{\phi}$ enhancements correspond to a loss of lock on $L 2$. The classical phase scintillation index $\sigma_{\phi}$, calculated by means of the standard cut-off frequency $(0.1 \mathrm{~Hz})$, shows large values in the presence of large TEC fluctuations, which lead to loss of lock on L2. These large values are strongly reduced when other cut-off frequencies are adopted. The proposed parameter $S_{\phi}$ provides information on the additional Doppler caused by small scale plasma density irregularities on GPS signals. Moreover, $S_{\phi}$ seems to be much more independent from the cut-off frequency choice and could offer a tool for retriev- ing physical information on the irregularities causing scintillation, such as the effective drift velocity.

\subsection{Scintilation maps}

Although the data availability for mapping small scale structure-related scintillations is rather poor, DLR has started developing a method for generating scintillation maps. The technique is analogous to the TEC mapping technique developed and used in DLR since 1995 (Jakowski, 1996; 1998). Basically, the scintillation maps are created by assimilating 

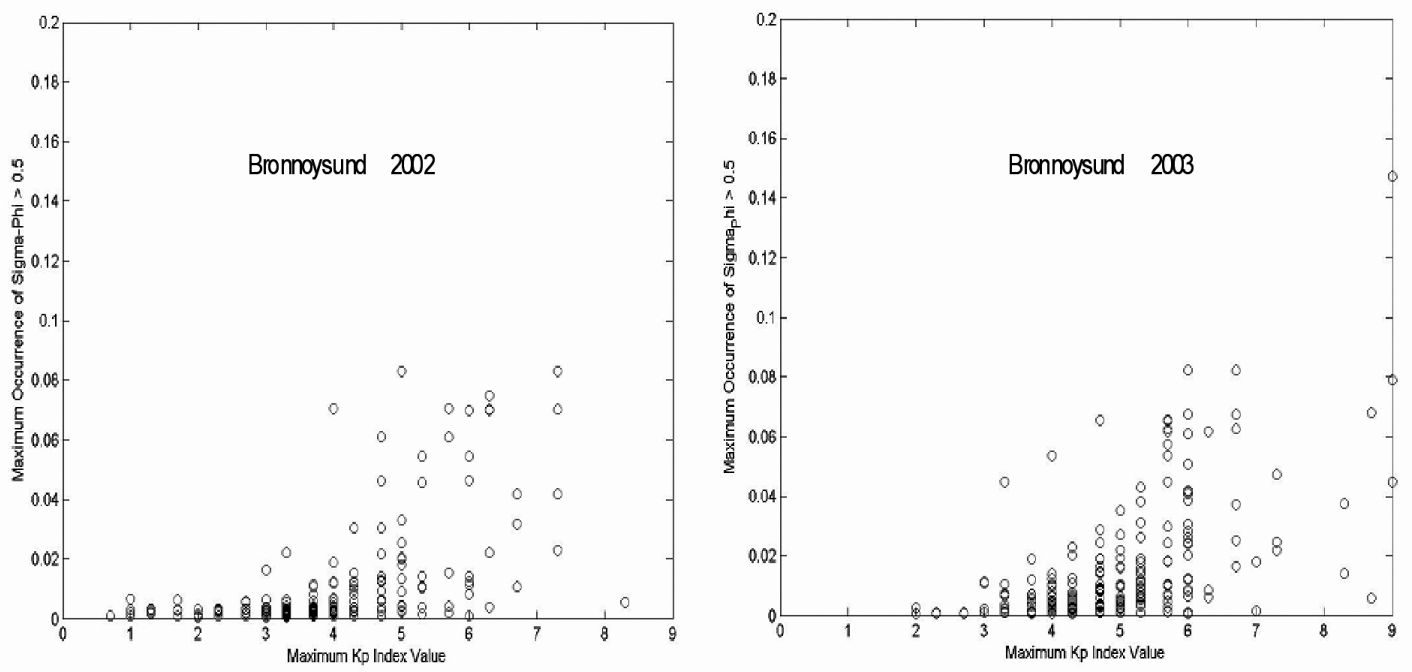

Fig. 17. Correlation between Kp and phase scintillation at Bronnoysund for the years of 2002 (left) and 2003 (right).

measured data into a background model. In case of scintillation mapping a suited scintillation model such as GISM (Béniguel, 2002) is used. Although we are aware of the limitations of the data density and model accuracy, the generation of scintillation maps is useful to learn more about mapping of scintillations. Scintillations are measured along the satellite - receiver links. For generating 2D - scintillation maps, the link related scintillation data, e.g. $S_{4}$, must be localized.

The measured scintillations are localized by assuming a single layer ionosphere as usually assumed for TEC-mapping. Doing so, the location of the measurement can be defined as the coordinates of the pierce point between the GPS link with the ionospheric shell at height $400 \mathrm{~km}$ as introduced earlier. The problem of mapping scintillation data measured at elevation e into equivalent vertical scintillation intensity which may act as a normalized reference is not yet solved. The definition of a mapping function requires more detailed investigation.

Regional scintillation maps are constructed by assimilating actual GPS-based scintillation measurements into a well specified scintillation model. To ensure a high reliability of the scin- tillation maps also in case of only a few measurements or at greater distances from the measuring points, the measured data are assimilated into the empirical scintillation model GISM (Béniguel, 2002). To obtain reliable scintillation values at the grid points, a weighting process between nearest measured and modelled values is carried out for each grid point value (e.g. grid spacing $2.5^{\circ} / 5^{\circ}$ in latitude/longitude). This method has the advantage that GPS users can compute scintillation activity from the constructed scintillation maps even in case of only a few or even missing observations. The results represent the measured scintillation data near the measuring points whereas at greater distances from measurements somewhat modified model values are provided. Depending on the number of available stations and the correlation length, the width of the weighting function can be modified in a proper way. The procedure may be applied to any scintillation parameter such as $S_{4}$ or $\sigma_{\varphi}$. A mapping sample is given in fig. 19, where only a few measurements from Bandung were used to construct a scintillation map for testing the procedure. Here the background model was fixed to the zero plane (no horizontal structure of scintillation activity). 

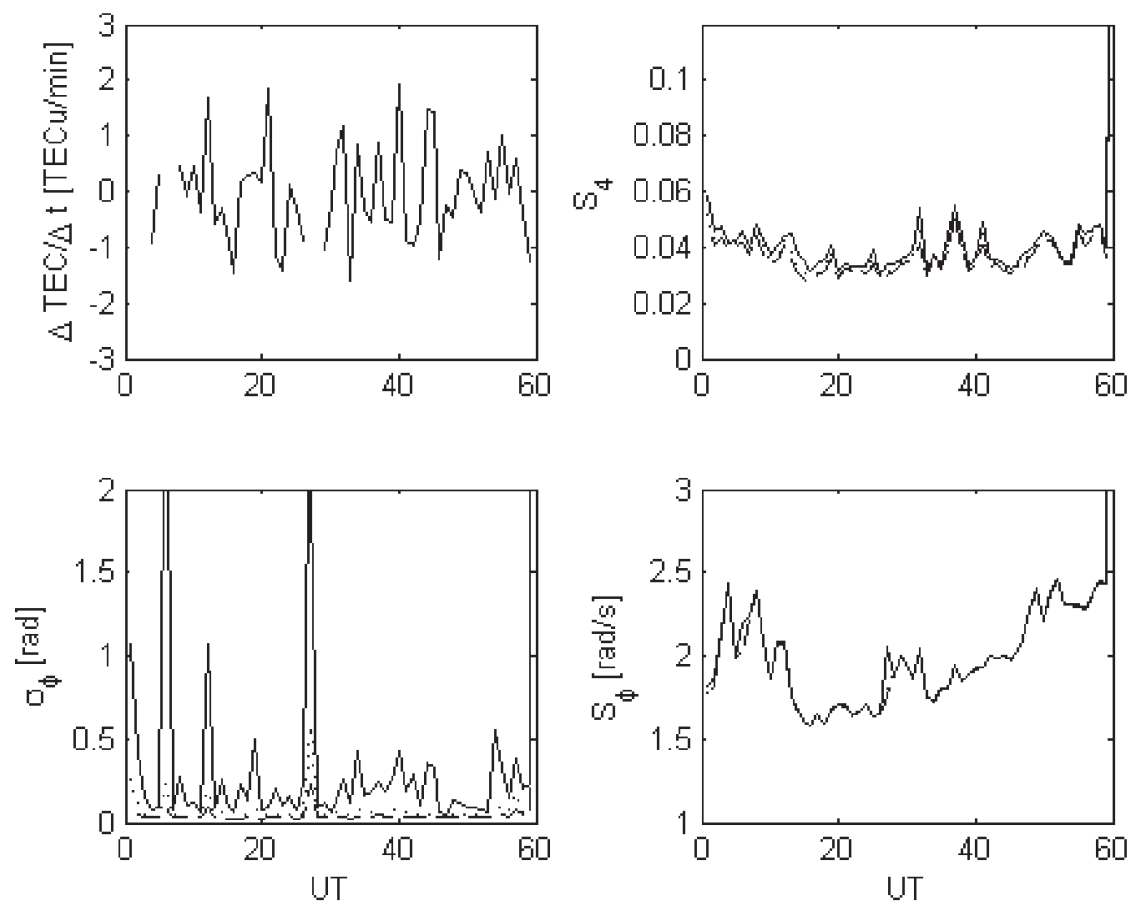

Fig. 18. TEC fluctuations and scintillation indices for PRN02 pass from 0700 to 0800 UT on the day 2007-01-30.

Applying a high quality scintillation model, existing data gaps can be reduced in a physical way. Since ionospheric models provide climatologic information, actual measurements may considerably deviate from the model. When constructing the scintillation maps, the correction is provided by the measurements. The more measurements are available, the higher the spatial resolution of the maps.

\subsection{Mitigation techniques}

Although the scintillation indices $S_{4}$ and $\sigma_{\phi}$ represent a practical measure of the intensity of amplitude and phase scintillation affecting GNSS receivers, they do not provide sufficient information regarding the actual tracking errors that degrade GNSS receiver performance when scintillation occurs. Suitable receiver tracking models, sensitive to scintillation (Conker et al., 2003), allow the computation of the variance of the output error of the receiver PLL (Phase Locked Loop) and DLL (Delay Locked Loop), which better expresses the quality of the range measurements used to calculate position. The capability of incorporating phase and amplitude scintillation effects into the variance of these tracking errors allows the application of relative weights (based on the inverse of these variances) to measurements from different satellites. This proposed mitigation technique gives the least squares stochastic model used for position computation a more realistic representation, in particular in a scintillation scenario, where the ionospheric irregularities affect each satellite differently. Collaboration involving the IESSG, UNESP (Sao Paulo State University, Brazil) and INGV has led to some promising results using this approach. Improvement in the height error 


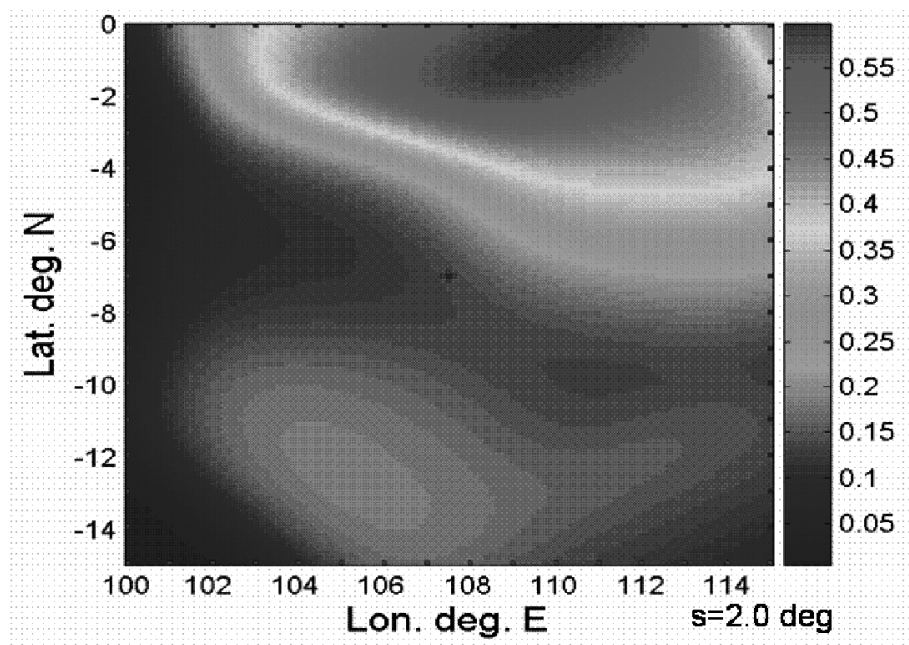

Fig. 19. $S_{4}$ maps based on measurements at the Bandung station.

when the technique is applied to relative positioning based on GPS $\mathrm{C} 1$ and P2 pseudoranges for baselines ranging from $1 \mathrm{~km}$ to $750 \mathrm{~km}$, at latitudes from $\sim 50^{\circ} \mathrm{N}$ to $\sim 79^{\circ} \mathrm{N}$, under different geomagnetic conditions $(4 \leq \mathrm{Kp} \leq 6)$, varied between $17 \%$ and $38 \%$.

To implement this mitigation approach when the carrier phase observable is involved it is necessary to access the power spectral density (PSD) of fluctuations in the carrier phase output, which is possible with the use of high rate data. Experiments were conducted by Aquino et al. (2008) where a mitigated solution based on pseudorange and carrier phase measurements was implemented and compared with the non-mitigated solution, for a baseline of $\sim 125 \mathrm{~km}$ between the INGV stations in Longyearbean (Lyb0) and Ny Alesund (Nya1). During a period of occurrence of high phase scintillation (fig. 20) it was observed that problems related to ambiguity resolution affecting positioning accuracy (height in particular) were reduced by the use of the proposed mitigated solution (figs. 21 and 22).

Details of these experiments are given in Aquino et al. (2009) and should be regarded as proof of concept. For practical future use of the method it is envisaged that the strategy pro- posed in Aquino et al. (2007) and further discussed in Strangeways (2008) may be applied.

\subsection{Case studies}

The investigation of case studies plays a crucial role in the understanding of the physical mechanisms causing scintillations on the signal passing through the ionospheric plasma. The scintillation effects, in fact, can be due to several phenomena such as electron precipitations, steep TEC gradients due to the presence of patchy irregularities, plumes of enhanced ionized plasma, etc. The last descending solar phase gave some opportunities of study during October and November 2003, when intense scintillation activity was recorded at high latitudes. During that period the IESSG and the IN$\mathrm{GV}$ receivers were in operation and their observations have been carefully analysed in relation to other sources of information. In particular, the adoption of the MIDAS (Multi Instruments Data Analysis System, Mitchell and Spencer, 2003) imaging technique, the use of a model to reproduce the ionospheric electrical potential (Weimer, 2001) and the integration with satellite data have been used to help the interpretation of 
Phi60 measured at station Nya1, 10 Dec 2006, 22-23UT

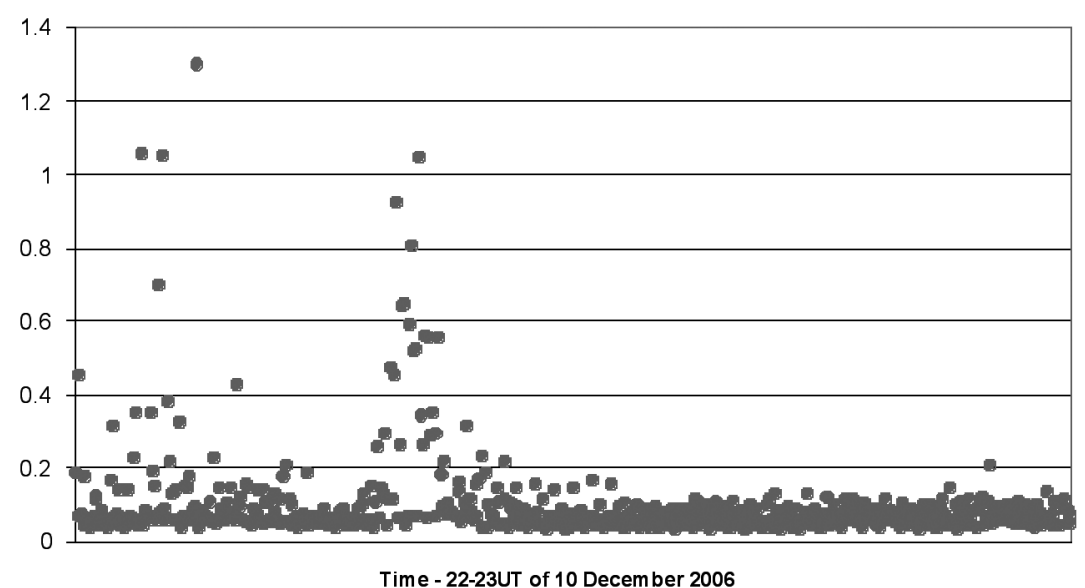

Fig. 20. Values of Phi60 between 22-23UT at station Nya1 on 10 Dec 2006.

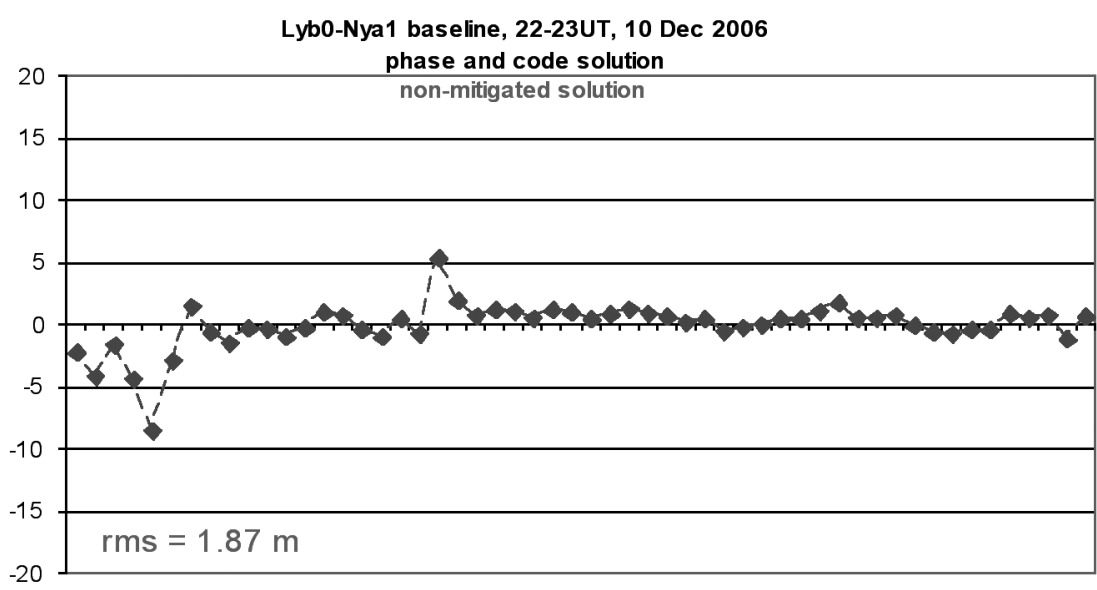

22-23UT, 10Dec06

Fig. 21. Height errors from pseudoranges and carrier phase solution without mitigation.

the GISTM experimental observations (Mitchell et al., 2005; De Franceschi et al., 2008). In these papers the authors verify the coincidence between steep TEC gradients and scintillation occurrence, also stressing the crucial role of the IMF Bz and By conditions in fragmenting the so called Tongue of Ionization (TOI) (Foster et al.,
2002) into polar cap patches (De Franceschi et al., 2008). In the same work De Franceschi et al. showed how the configuration of the convection cells in the polar ionosphere can significantly influence the velocity of the enhanced TEC structures seen by the GPS receivers. Currently, a first attempt of comparison between high and 


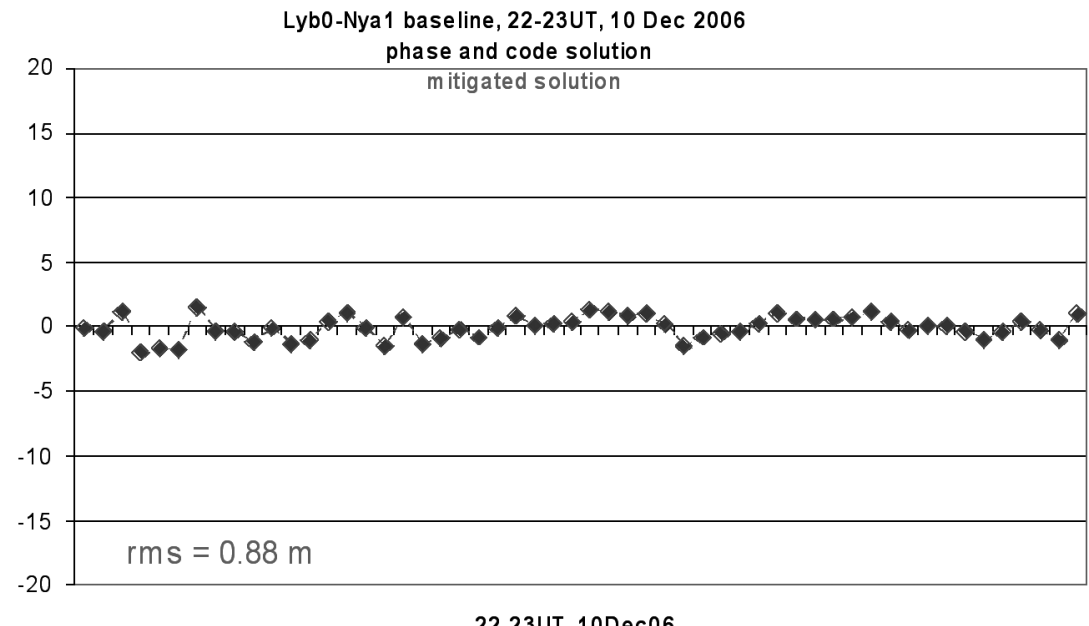

22-23UT, 10Dec06

Fig. 22. Height errors from pseudoranges and carrier phase solution with mitigation.

low latitudes scintillation effect is in progress analysing the measurements made by the GISTM receivers deployed in Vietnam by IETR (University of Rennes) and those made by the receivers located in Ny Alesund and at Mario Zucchelli Station. This work aims to highlight the different physical mechanisms causing scintillations over the poles and at the equator.

\section{Final remarks and IPDM project}

The satellites to ground links may be degraded due to propagation through the ionosphere plasma and its irregularities. These degradations may be significant at frequencies up to the $\mathrm{C}$ band. Crucially, this affects a number of applications increasingly relevant to modern society, such as satellite navigation, positioning, communications, remote sensing and earth observation. Ionosphere irregularities with spatial scales ranging from a few meters up to hundreds of metres may cause signal scintillations. Travelling Ionospheric Disturbances, magnetic storms and steep ionization gradients are also known to cause serious performance degradation on these systems. As their performance and reliability become more and more im- portant to the worldwide economy and society's daily activities, the need to establish robust integrated services to counter these effects becomes paramount. It is therefore a common interest of all European countries to reduce ionospheric threats to radio systems operating in quite different fields of application requiring high levels of accuracy, integrity and availability. Today's expanding availability of ground and space based Global Navigation Satellite Systems (GNSS) measurements, e.g. from GPS, GLONASS and GALILEO, lead to a unique combination of opportunities for continuously sounding the electron density structure of the ionosphere-plasmasphere system, prompting the idea of establishing a corresponding monitoring network. Such a monitoring system shall network and integrate all ionospheric monitoring services which already exist or are planned to be established by institutions in different European countries. The purpose of such a system will be to detect, monitor and forecast Ionospheric threats in a timely and reliable manner to the wider European user community. Since ionospheric weather is embedded in the overall space weather conditions, comprehensive space weather information, e.g. concerning solar radiation, solar wind, magnetospheric and geomagnetic state must be includ- 
ed in the information and data system.

The COST 296 activity has improved the expertise and capabilities to realize these objectives at the highest scientific and technological level in Europe. An established research base and strong expertise in different countries is available with respect to:

- GNSS measurement technique

- GNSS data archive, management and analysis

- Ionospheric scintillation research and impact on radio waves

- The development of mitigation techniques

The COST 296 community supports establishing an operational European-wide information service, capable of detecting and monitoring the whole spectrum of ionospheric perturbations and related scintillations (via geo-plasma warnings, now-casts and forecasts) for the wider European user community, including SME's, government offices and public users.

Considering existing national activities, and the cooperation activity supported during the COST 296 the current situation is mature enough for effective networking and integration of ionospheric services and to further develop them at a European level in an objective and concerted fashion. As a consequence of projects and scientific results obtained in the WP3.3 «ionospheric scintillation monitoring and modelling» of the COST 296, a proposal to form a consortium to establish an «Ionospheric Perturbation and Detection Monitoring (IPDM)» network in Europe was introduced. This could be the foundation of a research initiative and potentially a service that would meet the raised expectations.

\section{Acknowledgements}

The studies at the Polish Space Research Centre are sponsored by the Polish Ministry of Science and Higher Education through the grant IPY/280/2006. Part of this work was possible thanks to a free access to NSSDC archives. Part of the scintillation data used in this report were kindly provided by C. Mitchell at the University of Bath (UK) through an EPSRC project. The INGV authors thank the PNRA (Italian National Program for Antarctic Researches) and POLARNET-CNR. The work by MM has been partially supported by the contract ASI/ISMB/ASI N.I./006/07/0. BF thanks the Slovenian Research Agency for supporting his activity at the University of Nova Gorica. DLR thanks LAPAN/Indonesia for supporting the high rate GPS measurements in Bandung. Collaboration between the IESSG, INGV and UNESP has been facilitated by two Royal Society International Joint Project grants. The work carried out by the IESSG on the 2001-2003 data was sponsored by an EPSRC grant, which also funded the purchase and deployment of the GISTM receivers used in the experiments.

\section{REFERENCES}

AdAM, J-P, Y. BÉniguel, N. JAKowski, T. NoACK, V. Wilken, J-J Valette, M. Cueto, A. Bourdillon, P. LASSUdRIE-DuCHESNe and B. Arbesser-RastburG (2008): Analysis of scintillation recorded at low and high latitudes during the PRIS measurement campaign, (IES Symposium, Alexandria, Va, May 2008).

Aquino, M., T. Moore, A. Dodson, S. Waugh, J. Souter and F.S. Rodrigues (2005a): Implications of ionospheric scintillation for GNSS users in Northern Europe, Journal of Navigation, 58 (2), 241-256.

Aquino, M., F. Rodrigues, J. Souter, T. Moore, A. Dodson and S. WAUGH (2005b): Ionospheric scintillation and impact on GNSS users in Northern Europe: Results of a 3 year study, Space Communications, 20 (1/2), 17-30.

Aquino, M., M. Andreotti, A. Dodson and H. StrangeWAYS (2007): On the Use of Ionospheric Scintillation Indices as Input to Receiver Tracking Models, Journal Advances in Space Research, 40 (3), 426-435.

Aquino, M., J.F.G. Monico, A. Dodson, H. Marques, G. De FRANCESCHI, Lu. ALFONSI, V. ROMANO and M. ANDREOTTI (2009): Improving the GNSS Positioning Stochastic Model in the Presence of Ionospheric Scintillation, Journal of Geodesy, doi:10.1007/s00190-009-0313-6.

Basu, Su., Sa. Basu, E. Costa, C. Bryant, C.E. ValLADARES and R.C. LIVINGSTON (1991): Interplanetary magnetic field control of drifts and anisotropy of highlatitude irregularities, Radio Sci., 26, 1079-1103.

BÉNIGUEL, Y. (2002): Global Ionospheric Propagation Model (GIM): a propagation model for scintillations of transmitted signals, Radio Science, 37 (3).

Bhattacharyya, A., S. Basu, K.M. Groves, C.E. ValLADARES and R. SHEEHAN (2001): Dynamics of equatorial $F$ region irregularities from spaced receiver scintillation observations, Geophys. Res. Lett., 28, 119-122.

BRIGGS, B.G. and I.A. PARKIN (1963): On the variation of radio star and satellite scintillations with zenith angle, J. Atmos. Terr. Phys., 25, 339-365. 
CANnon, P.S., K. GRoves, D.J. Fraser, W.J. Donnelly and K. Perrier (2006): Signal distortion on VHF/UHF transionospheric paths: First results from the Wideband Ionospheric Distortion Experiment, Radio Sci., 41, RS5S40, doi:10.1029/2005RS003369.

Coco, I., E. Amata, G. De Franceschi, L. Alfonsi, V. Romano, M.F. Marcucci, M. Lester and P.L. Dyson (2007): Statistical Correlation between GPS Scintillations and HF backscatter, (IUGG XXIV General Assembly July 2-13, 2007 Perugia, Italy).

ConKer, R.S., M.B. El-Arini, C.J. Hegarty and T. HsiaO (2003): Modelling the Effects of Ionospheric Scintillation on GPS/Satellite-Based Augmentation System Availability, Radio Science, 38 (1), 1001, doi:10.1029/2000RS002604, 2003.

Costa, E., P.F. Fougere and SA. BASU (1988): Cross-correlation analysis and interpretation of spaced-receiver measurements, Radio Sci., 23, 141-162.

De Franceschi, G., L. Alfonsi and V. Romano (2006) ISACCO: an Italian project to monitor the high latitudes ionosphere by means of GPS receivers, GPS Solution, doi:10.1007/s10291-006-0036-6.

De Franceschi, G., L. Alfonsi, V. Romano, M. Aquino, A. Dodson, C.N. Mitchell, P. SPENCER and A.W. WERNIK (2008): Dynamics of high-latitude patches and associated small-scale irregularities, J. Atmos. Sol.-Terr. Phys., 70, 879-888, doi:10.1016/j.jastp.2007.05.018.

FORTE, B. (2005): Optimum detrending of raw GPS data for scintillation measurements at auroral latitudes, $J$. Atmos. Sol-Terr. Phys., 67, 1100-1109.

Foster, J.C., P.J. ERICKSON, A.J. Coster, J. Goldstein and F.J. RICH (2002): Ionospheric signatures of plasmaspheric tails, Geophys. Res. Lett., 29 (13), 1623, doi:10.1029/2002GL015067.

Gherm, V.E., N.N. Zernov and H.J. Strangeways (2005a): Propagation Model for Transionospheric Fluctuational Paths of Propagation: Simulator of the Transionospheric Channel, Radio Science, 40 (1), RS1003, doi:10.1029/2004RS003097.

GHERM, V.E., N.N. Zernov and H.J. Strangeways (2005b): HF Propagation in a Wideband Ionospheric Fluctuating Reflection Channel: Physically Based Software Simulator of the Channel, Radio Science, 40 (1), RS1001, doi:10.1029/2004RS003093.

GHERM, V.E., N.N. ZERNOV and H.J. STRANGEWAYs (2006): Effect of scintillations on the correlation of differentfrequency L-band satellite navigation signals on the same transionospheric link, presented at the 1st European Conference on Antennas and Propagation (Eu$C A P)$, (Nice, France, 6-10 November 2006), published on Conference Proceedings CD.

Gherm, V.E., N.N. Zernov and H.J. Strangeways (2007a): Effect of scintillation on the correlation between different frequency L-band transmissions, presented at the International Beacon Satellite Symposium, (Boston, USA, 11-15 June 2007), published on Conference CD.

GHerm, V.E., N.N. Zernov and H.J. Strangeways (2007b): Correlation of different frequency L-band satellite navigation signals on the same transionospheric link for scintillation conditions, presented at COST 296/IRI meeting in Prague, (Czech Republic, 10-14 Ju1y, 2007), published on the Conference website.
GHERM, V.E., N.N. Zernov and H.J. STRAngeways (2007c): Modelling of the Effect of Strong Scintillation on GPS Signals due to Plasma Bubbles in the Low-Latitude Ionosphere, presented at the International Beacon Satellite Symposium, (Boston, USA, 11-15 June 2007), published on Conference Proceedings CD.

Gherm, V.E., N.N. Zernov and H.J. Strangeways (2007d): Modelling of L-band signals scintillation in the conditions of equatorial plasma bubbles, paper presented at the 20th UK URSI Colloquium at Portsmouth University, (2-3 July 2007).

GHerm, V.E., N.N. Zernov and H.J. StRangewaYs (2007e): Modelling of the effect of strong scintillation on GPS Signals due to plasma bubbles in the low-latitude ionosphere, presented at COST 296/IRI meeting in Prague, (Czech Republic, 10 -14 July, 2007), published on the Conference website.

GSV 4004B (2005): GPS Ionospheric Scintillation \& TEC Monitor (GISTM) User's Manual, (GSV GPS Silicon Valley).

JAKOWSKI, N. (1996): TEC Monitoring by Using Satellite Positioning Systems, in Modern Ionospheric Science, edited by H. KoHL, R. Rüster and K. SCHLEGEL, (EGS, Katlenburg-Lindau, ProduServ GmbH Verlagsservice, Berlin), pp. 371-390.

JAKOWSKI, N. (1998): Generation of TEC Maps Over the COST Area Based on GPS Measurements, Proc. 2nd COST251 Workshop, (Ed. A. Vernon), 30-31 March, 1998, Side, pp. 51-57.

Kil, H., P.M. Kintner, E.R. DE Paula and I.J. Kantor (2000): Global Positioning System measurements of the ionospheric zonal apparent velocity at Cochoeira Paulista in Brazil, J. Geophys. Res., 105, 5317-5327.

Kintner, P.M., H. KiL, T.L. BeACH and E.R. DE PAUla (2001): Fading timescales associated with GPS signals and potential consequences, Radio Sci., 36, 731-743.

Kintner, P.M., B.M. Ledvina, E.R. DE PaUla and I.J. KANTOR (2004): Size, shape, orientation, speed, and duration of GPS equatorial anomaly scintillations, Radio Sci., 39, RS2012, doi: 10.1029/2003RS002878.

LEDVINA, B.M., P.M. KinTNER and E.R. DE PAULA (2004): Understanding spaced-receiver zonal velocity estimation, $J$. Geophys. Res., 109, A10306, doi:10.1029/2004JA010489.

Livingston, R.C., C.L. Rino, J. Owen and R.T. TsunodA (1982): The anisotropy of high-latitude nighttime F region irregularities, J. Geophys. Res., 87, 10519-10526.

MATERASSI, M. (2008): Use of ROSA data in Space Weath$e r$, invited talk to the URSI XXIX General Assembly, (Chicago 16-17 August 2008).

Materassi, M., A.W. WeRniK and L. Alfonsi (2008): The WAM scintillation model: overview and application to ionospheric studies, talk given at the COST Workshop «Ionospheric scintillation: scientific aspects, space weather application and services», (Nottingham, UK, 20-22 February 2008).

Materassi, M., Lu. Alfonsi, G. De Franceschi, V. RoMANO, C.N. Mitchell and P. SPALla (2009): Detrend effect on the scalograms of GPS amplitude scintillation, J. Adv. Space Res., doi:10.1016/j.asr.2008.01.023.

Maurits, S.A., V.E. GHERM, N.N. Zernov and H.J. STRANGEWAYs (2008): Modeling of scintillation effects on high-latitude transionospheric paths using ionospheric model (UAF EPPIM) for background electron 
density specifications, Radio Science, 43, RS4001, doi:10.1029/2006RS003539.

Mitchell, C.N. and P.S.J. SPENCER (2003): A three-dimensional timedependent algorithm for ionospheric imaging using GPS, Ann. Geophys., 46, 687-696.

Mitchell, C.N., L. Alfonsi, G. De Franceschi, M. LESTER, V. ROMANO and A. W. WERNIK (2005): GPS TEC and scintillation measurements from the polar ionosphere during the October 2003 storm, Geophysical Research Letters, 32, L12S03, doi:10.1029/2004GL021644, 2005.

Otsuka, Y., K. Shiokawa and T. Ogawa (2006): Equatorial ionospheric scintillations and zonal irregularity drifts observed with closely-spaced GPS receivers in Indonesia, J. Meteorological Soc. Japan, 84A, 343351.

RinO, C.L. (1982): On the Application of Phase Screen Models to the Interpretation of Ionospheric Scintillation Data, Radio Sci., 17 (4), 855-867.

Rino, C.L. and R.C. Livingston (1982): On the analysis and interpretation of spaced-receiver measurements of transionospheric radio waves, Radio Sci., 17, 845-854.

Rodrigues, F.S., M.H.O. Aquino, A. Dodson, T. Moore and S. WAUGH (2004): Statistical analysis of GPS ionospheric scintillation and short-time TEC variations over Northern Europe, Journal of the Institute of Navigation, 51 (1), 59-75.

Rogers, N.C., P.S. CANNON and K.M. GRoves (2008): Measurements and Simulation of the Ionospheric Channel Scattering Function for the ALTAIR VHF/UHF Radar, Paper A086, 12th International Ionospheric Effects Symposium, (May 13-15 2008, Alexandria, VA, J.M. Goodman (Editor-in-chief), National Technical Information Service (NTIS), Springfield VA).

Romano, V., S. Pau, M. Pezzopane, E. Zuccheretti, B. Zolesi, G. De Franceschi and S. Locatelli (2008): The electronic Space Weather upper atmosphere (eSWua) project at INGV: advancements and state of the art, Ann. Geophys., 26, 345-351.

Spogli L., L. Alfonsi G. De Franceschi, V. Romano, M. Aquino and A. Dodson (2009): Climatology of the Ionospheric Scintillations over the Auroral and Cusp European Regions, Geophysical Research Abstracts, Vol. 11, EGU2009-7396, EGU General Assembly 2009.

Strangeways, H.J., V.E. GHERM and N.N. ZERNOV (2006): Transionospheric simulator for strong scintillation conditions and its use in quantifying scintillation effects for GNSS systems, Proceedings of the 10th International Conference on Ionospheric Radio Systems, and Techniques, (London, 18-21 July 2006), pp. 173-177.

Strangeways, H.J., V.E. GHERM and N.N. Zernov (2007a): Modelling and mitigation of the effect of scin- tillations on GPS, invited paper at 49th International Symposium ELMAR-2007, (12-14 September, 2007, Zadar, Croatia), published in conference proceedings.

Strangeways, H.J., V.E. Gherm and N.N. Zernov (2007b): Modelling and mitigation of the effect of ionospheric scintillations on GPS due to time-varying electron density irregularities and plasma bubbles, invited paper at the Workshop on Global Navigation Satellite Systems (GNSS): problems, vulnerabilities and solutions, (Baska, Krk Island, Croatia, 12-14 September 2007).

Strangeways, H.J. (2008): Determining scintillation effects on GPS receivers, in Ionospheric Effects Symposium IES2008, (Alexandria,Virginia, USA, 13-15 May 2008).

Tiwari, D., B. Engavale, A. Bhattacharyya, C.V. Devasia, T.K. PANT and R. SRIDHARAN (2006): Simultaneous radar and spaced receiver VHF scintillation observations of ESF irregularities, Ann. Geophys., 24, 1419-1427.

VAn Dierendonck, A.J., J.A. Klobuchar and Q. Hua (1993): Ionospheric scintillation monitoring using single frequency C/A code receivers, ION GPS 1993.

YeH, C.K. and C.H. LiU (1982): Radio wave scintillations in the ionosphere, Proc. IEEE, 70 (4), 324-360.

WeIMER, D.R. (2001): An improved model of ionospheric electric potentials including substorm perturbations and application to the Geospace Environment Modeling November 24, 1996, event, J. Geophys. Res., 106, 407-416.

Wernik, A.W., C.H. LiU and K.C. YeH (1983): Modeling of spaced-receiver scintillation measurements, Radio Sci., 18, 743-764-.

Wernik, A.W., L. Alfonsi and M. Materassi (2004): Ionospheric irregularities, scintillation and its effect on systems, Acta Geophysica Polonica, 52 (2), 237-249.

WerNiK, A.W., L. AlFONSI and M. MATERASSI (2007): Scintillation modelling using insitu data, Radio Sci., 42 (1), RS1002, doi:10.1029/2006RS003512.

Wernik, A.W., M. Pozoga, M. GrzesiaK, A. RoKicki and M. MoRAwSKI (2008): Monitoring ionospheric scintillation and TEC at the Polish Polar Station on Spitsbergen: Instrumentation and preliminary results, Acta Geophysica, 56 (4), doi: 10.2478/s11600-008-0060-8

ZeRnOv, N.N., V.E. GHERM and H.J. STRANGEWAYs (2008a): The scintillation propagation model for the effects of scintillation on transionospheric paths traversing midscale ionospheric inhomogeneities, in COST296 Workshop «Ionospheric scintillation: Scientific aspects, Space weather, Application and services», (Nottingham, UK, 20-22 February, 2008).

Zernov, N.N., V.E. GHERM and H.J. Strangeways (2008b): On the effects of scintillation on the transionospheric paths of propagation, in Proceedings of IES2008, (Alexandria, Virginia, USA, 13-15 May, 2008), p. 8. 